\title{
Optimisation of thin-walled hybrid vertical struts for crashworthy aircraft designs
}

\author{
J. Paz ${ }^{1}$, J. Díaz ${ }^{2}$, L. Romera ${ }^{3}$, \\ Universidade da Coruña - Structural Mechanics Group, School of Civil Engineering \\ 15071 A Coruña, Spain \\ F. Teixeira-Dias ${ }^{4}$, \\ The University of Edinburgh - School of Engineering, Edinburgh EH9 3JL, UK
}

\begin{abstract}
This research concerns the crashworthiness enhancement of a model of a Boeing 737200 fuselage section. Using a validated numerical specimen, four thin-walled crushable hybrid energy absorbers are added to the aircraft to work as vertical struts. The absorbers are composed of a hollow aluminium tube, a star-shaped glass-fibre reinforced polymer inner matrix and foam extrusions. The absorbers - with variable tube edge and thickness, composite thickness and core height — are single- and multi-objectively optimised. Surrogate models and genetic algorithms are used for the minimisation of acceleration loads, injury levels and the strut's weight. Results yield a more efficient frames' collapse evolution with plastic dissipation increased by over $50 \%$. Consequently, acceleration peaks are up to $50 \%$ lower at the two measured locations while maintaining low mass values. Injury levels were also reduced from severe to moderate according to an Eiband diagram. Keywords: Aircraft design, Crashworthiness, hybrid energy absorbers, biometric criteria, multi-objective optimisation, surrogate models, genetic algorithms
\end{abstract}

\section{Introduction}

Aircraft's edge over other forms of transport resides in its versatility, speed, and safety. In the last decade, the fatality rate per billion passenger-miles for aircraft travel was 750 times lower than for road transport [1]. In the event of an airplane crash, however, severe and life-threatening injuries are more prone to occur than in any other transport areas. To address this issue, the military, commercial, and general aviation industries have adopted crashworthiness as a vital design criterion in the design process. This safety enhancement

\footnotetext{
${ }^{1}$ Post-Doc researcher. Corresponding author. Tel: +34 881016 017; Fax: +34 981167170

${ }^{2}$ Associate Professor

${ }^{3}$ Associate Professor

${ }^{4}$ Senior Lecturer
} 
of aircraft originates from Hugh DeHaven's generic principles for crashworthy structural design: ensuring the structures around the liveable spaces dissipate energy to protect the occupants and transmitting loads to the strongest parts of the structure [2].

Different approaches have been sought over the past five decades to successfully apply these guidelines and improve passenger protection through both experiments and numerical simulations $[3,4]$. Authors have considered several scenarios, including explosions, foreign object impacts or hard landing crashes [5]. During the latter, the vertical deceleration is critically influenced by the sub-floor structures [6]. In the commercial aircraft range, the highest contribution for kinetic energy dissipation stems from deformation of the main fuselage [7]. After the sub-cargo area impacts the ground, the crushing process then stresses the main circumferential frames, which collapse locally in the form of plastic hinges [8].

In order to improve the aircraft's response in hard landing or water ditching situations, the main areas of analysis have typically been the sub-floor area [9], the main frames [10], and the vertical struts [11]. Ren et al. [12] showed that modified and enhanced subcargo regions with structures including honeycomb and foam reinforcements delivered remarkable energy absorption capabilities. When studying the primary frame structures, Schatrow and Waimer's [13] improved crash concept example delivered a smoother energy absorption through parallel activation processes.

The implementation of vertical support struts or continuous corrugated composite plates [14] provides additional support for the passenger floor. Several investigations have assessed the effect of struts as crashworthy elements [15, 16]. Yiru et al. [17] determined that the strut's stiffness was a key factor for damping acceleration loads and maintaining a liveable crush space. While stiff struts avoid excessive crushing of the sub-floor area and reduce the risk of bottoming-out, they also transmit higher force peaks to the occupants; thus suggesting the need for a trade-off between the two desired responses [18]. The position and angle of the struts within the fuselage is also critical for occupant protection, as they influence the aforementioned plastic hinge location. By discretely modifying the insertion angles with the floor beams and the main frames, Ren and Xiang [11] concluded that best energy absorption and acceleration trends were obtained for oblique struts, albeit sacrificing cargo space. Ren and Xiang [19] also confirmed the benefits of trigger implementation, with peak accelerations being reduced by over $12 \%$.

In order to enhance the response of these tubular structures, inner reinforcements are usually added to complement tube's failure behaviour [20]. Thin-walled metallic tubes 
are commonly used when designing crushable energy absorbers, usually working as the confining structure. Steel and aluminium are common given their ductility and high energy absorption capabilities. As for the inner reinforcement, many materials and designs have been explored over the last years, including cork compounds [21, 22], wood [23], fibre-reinforced polymers (FRPs) [24, 25], metals [26], and foams of various natures [2729]. The usage of these has gained importance in the aircraft industry, where they are now used in primary and secondary structures due to the high strength to weight ratios [3032]. When the struts are filled, the ductile collapse process of the outer tube is modified so as to obtain a stable crushing $[33,34]$ which, in turn, is achieved by obtaining a higher number of ordered folds, which yields a smoother mechanical response and higher energy absorption values [35].

For this research, the fuselage section of the Boeing 737-200 is used [36]. This aircraft model, conceived in the mid 1960s, was not designed according to nowadays crashworthiness standards [37]. Therefore, it becomes a suitable candidate to be fitted with hybrid energy absorbers (HEAs) acting as crushable vertical struts. The specimen - the fuselage section - undergoes a hard landing, and the effect of a baseline absorber on the passengers is monitored with crashworthiness metrics. Seeking a better response from the aircraft, the absorbers are parametrised with the ultimate goal of optimisation. For this, a Moving Least Squares (MLS) surrogate model is built using the Latin Hypercube Sampling (LHS) technique as they have delivered the best results in previous surrogate-based optimisation procedures where Gaussian processes (Kriging) and multivariate adaptive regression splines (MARS) were used [38, 39]. Later on, the vertical struts are optimised using single- and multi-objective genetic algorithms. The peak acceleration loads at two locations, the injury level, and the structure's weight are minimised.

\section{Structural components}

\subsection{Selection of test scenario}

For the following study, a hard landing scenario of a Boeing 737-200 fuselage section is analysed. The aircraft is dropped from a height of 4.27 meters, impacting the ground at $9.144 \mathrm{~m} / \mathrm{s}$, constituting a severe but survivable crash [40]. A validated numerical model [36] is used as a starting point for crashworthiness improvement. Two scenarios were studied in this investigation, including and excluding the auxiliary fuel tank in the cargo area. Since the latter case delivered the most severe results - the fuel tank dissipates a significant amount of the vertical kinetic energy — it is chosen for this research. 


\subsection{Hybrid Energy Absorbers}

Seeking the crashworthiness improvement of the aircraft, vertical struts are to be added within the main fuselage structures. Rather than using traditional bar elements that only undergo localized plastic dissipation at the hinge formation area [41], thinwalled crushable components are preferred for their higher energy absorption capabilities. Furthermore, hybrid designs deliver improved crashworthiness responses than singlecomponent counterparts in terms of specific energy absorption and smoothness of the response [35, 38, 39].

As a first approach, the honeycomb-filled energy absorbers as those developed by Paz et al. [39] are added to the model. After a number of preliminary tests, however, they seemed too rigid for the impact conditions of this study, developing only one fold at most and barely deforming in the post-buckling region, as seen in figures 1a and 1b. Moreover, little energy was dissipated, resulting in low sub-floor deformation on account of excessive acceleration peak loads and significantly drawing the Eiband graph onto the severe-injury region. Following the same concept, a version of the hybrid absorbers offering lower stiffness and complexity was considered, also combining metal, glass-fibre reinforced polymer (GFRP), and foam structures. These devices, inspired by the designs from Costas et al. [42, 43], are now composed of an outer aluminium tube filled with a star-shaped structure and foam extrusions filling the triangular cells in-between the composite plates. Since the overall amount of GFRP (the stiffest reinforcing material) is significantly reduced with the skeleton configuration, the absorbers require lower initial triggering loads to undergo progressive collapse.

The square-sectioned tube is $200 \mathrm{~mm}$ long as it provides enough crush stroke; and it is connected to the fuselage via vertical circular-sectioned beams stiffer than the tube. The values for the axial stiffness of the upper and lower bars is $3.90 \mathrm{kN} / \mathrm{m}$ and $34.1 \mathrm{kN} / \mathrm{m}$ respectively, which ensures the tube's collapse under the studied impact conditions. Bars with smaller inertias could lead to undesired failure or global buckling effects, while larger beams would notably increase the component's mass. These beams are connected with the passenger floor spars and the lower section of the frames with knuckle joints that allow rotation around the longitudinal axis of the fuselage. Two rigid plates are welded to the other ends of the vertical bars to distribute the crushing loads along the top and bottom edges of the tube. Moreover, the HEAs are rotated $45^{\circ}$ degrees on the vertical axis to reduce global buckling on the longitudinal direction. The complete assembly of this device is shown in figure 2. 


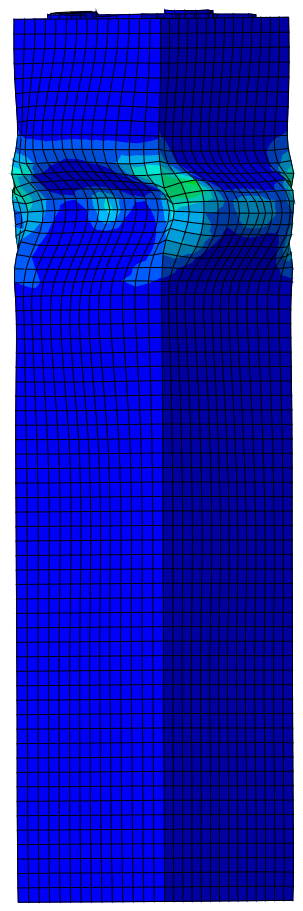

(a) Outer tube deformation.

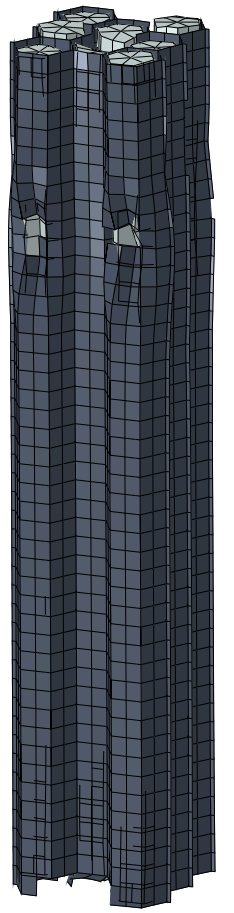

(b) Inner reinforcement.

Figure 1: Post-test deformation of honeycomb- and foam-filled hybrid energy absorber featured as vertical strut.

Furthermore, a $2 \mathrm{~mm}$ trigger is implemented on the lower tube end to reduce high initial peak forces and ease a stable collapse of the structure by adding four kinks at the center of each tube edge [42]. Figure 3 shows the trigger locations and displacement direction implemented on the tube.

The tube's inner core is made from an intertwined four-plate star-shaped structure and triangular foam extrusions filling the gap between tube and reinforcement. As done in previous simulations with hybrid absorbers, a $1 \mathrm{~mm}$ gap is left between the core and tube to ease the insertion of the reinforcement within the tube as well as avoiding computational instabilities from initial overclosures or penetration.

A 3-dimensional cut of the hybrid absorber is presented in figure 4, where two of the design variables are shown. In the meshed top view from figure 5, the inner core configuration and the final two variables are also represented.

\subsection{Materials}

Given the highly-nonlinear nature of these numerical simulations and the wide range of loading conditions in which materials are solicited, detailed material models are deemed necessary to capture complex behaviours as strain-rate sensitivity, damage and failure, or pressure-dependent yield surfaces. Hereunder, the material models used in this investiga- 


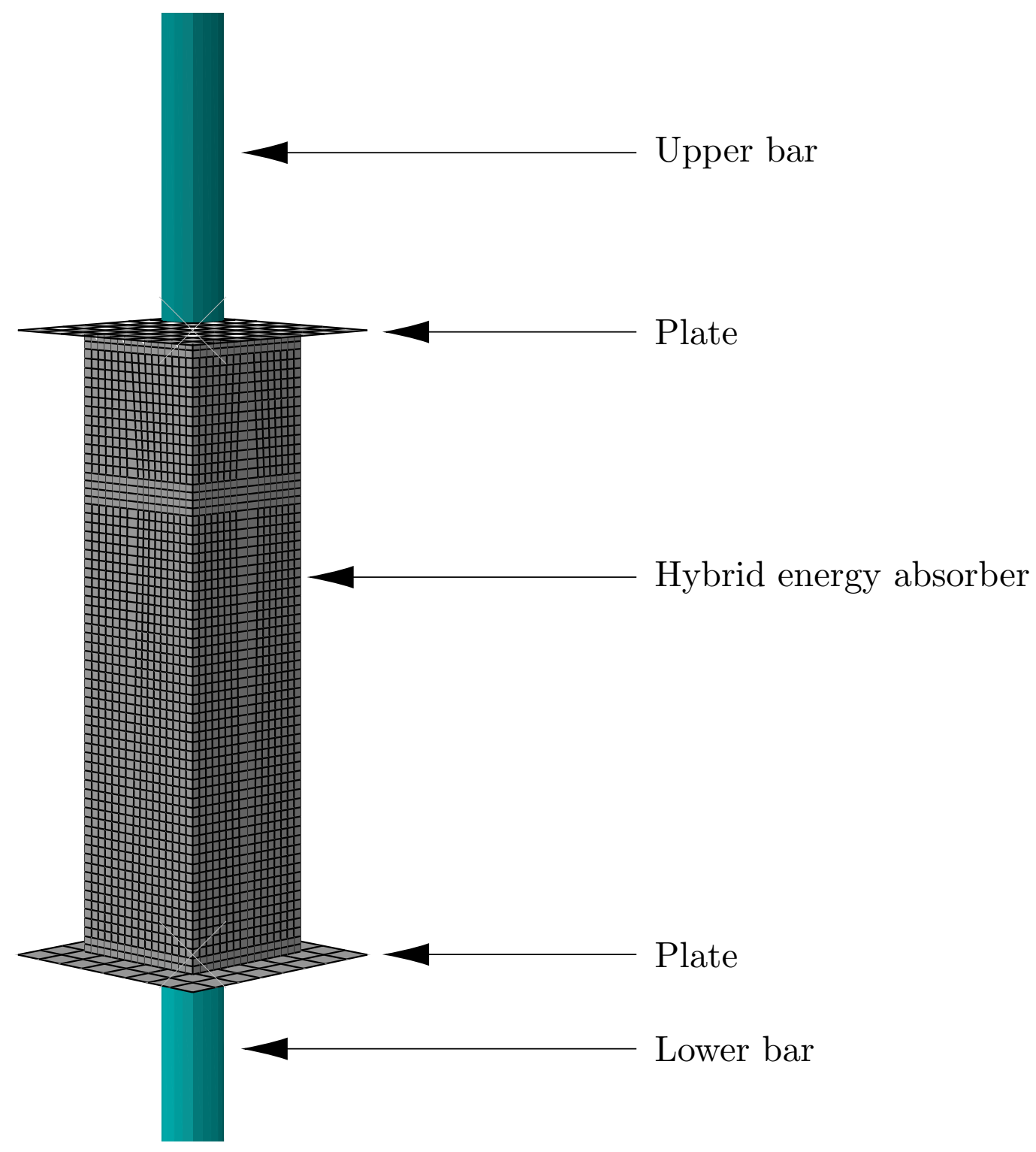

Figure 2: Mesh detail of hybrid energy absorber with load-transmitting bars and rigid plates.

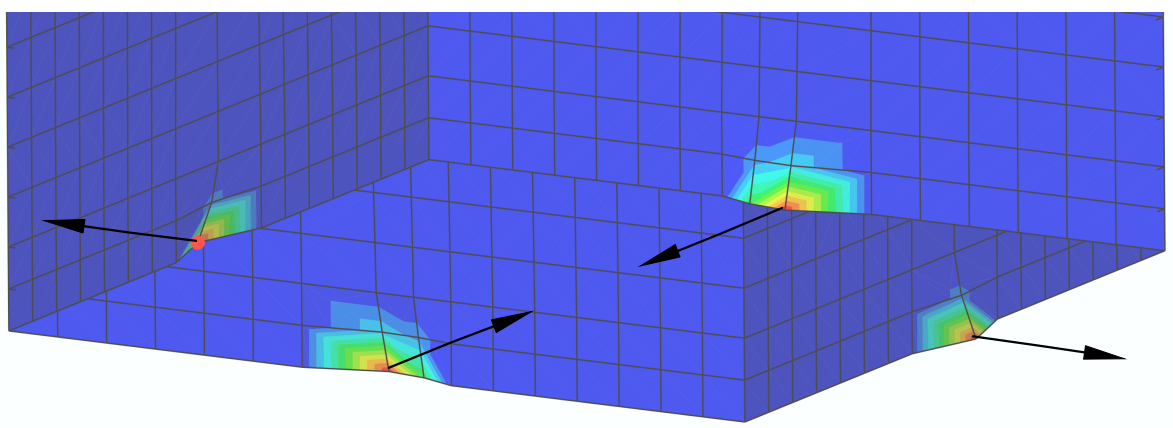

Figure 3: $2 \mathrm{~mm}$ trigger on lower edges of the HEA. 


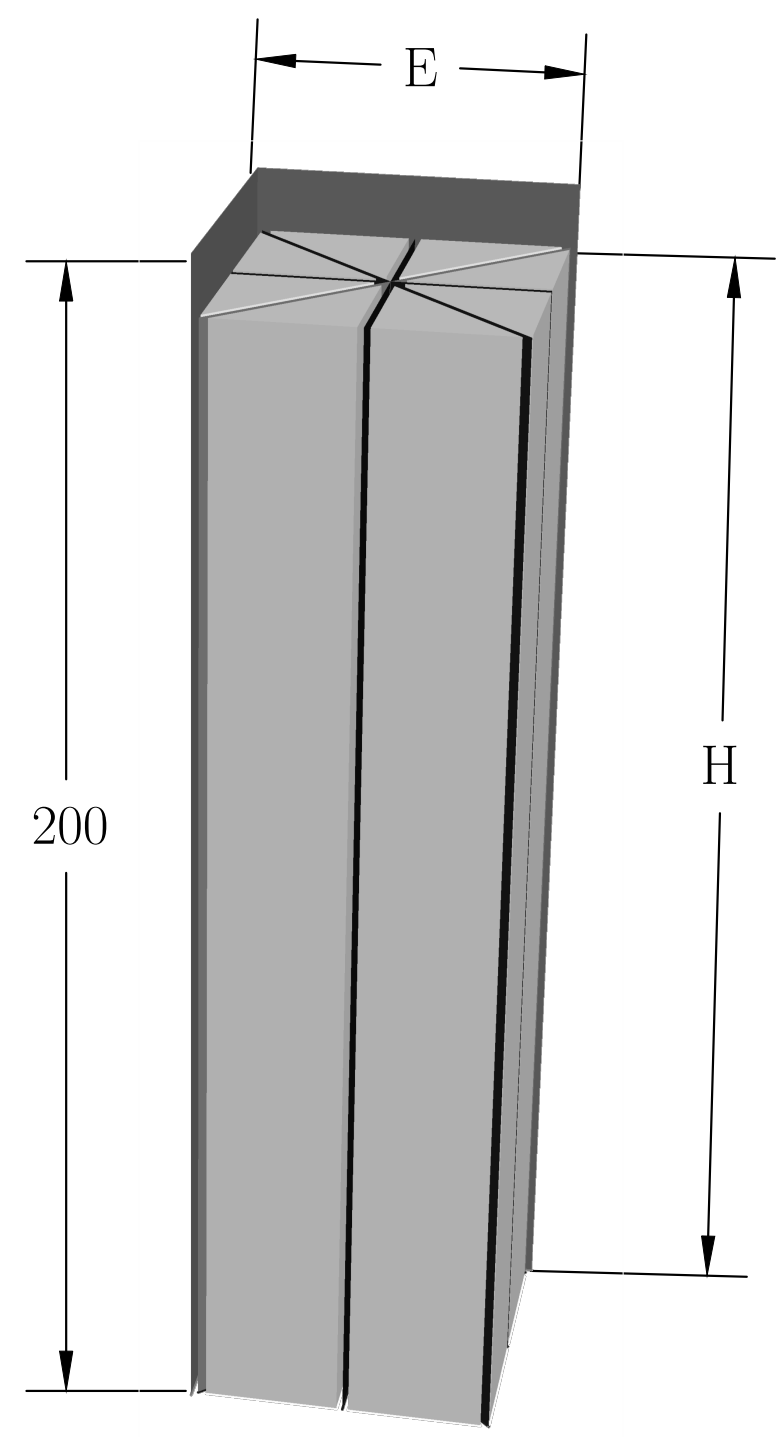

Figure 4: 3-dimensional cut of the hybrid energy absorber. Dimensions in millimetres.

tion are described.

The fuselage section is made from two different metals. The aluminium alloy AA7075T6 is used for the frames, under-floor beams and stringers. The fuselage skin and floor, however, are made of AA2024-T3 aluminium. Both materials are modelled according to the modified Johnson-Cook strain-rate sensitive plasticity model [44] without temperature effects. The plasticity constitutive equation for the aluminium is

$$
\sigma_{y}=\left[A+B\left(\varepsilon_{p}^{e f f}\right)^{n}\right]\left(1+C \ln \dot{\varepsilon}^{*}\right),
$$

where $A$ is the material's yield strength, $B$ is the hardening law's amplitude modifier, $\varepsilon_{p}^{\text {eff }}$ is the effective plastic strain, $\dot{\varepsilon}^{*}=\dot{\varepsilon} / \dot{\varepsilon}_{0}$ is the dimensionless equivalent plastic strain-rate, $n$ is the hardening law shape modifier, and $C$ is the strain-rate's dependency modifier. The material properties are taken from Kay [45] for the AA2024-T3 aluminium and from 


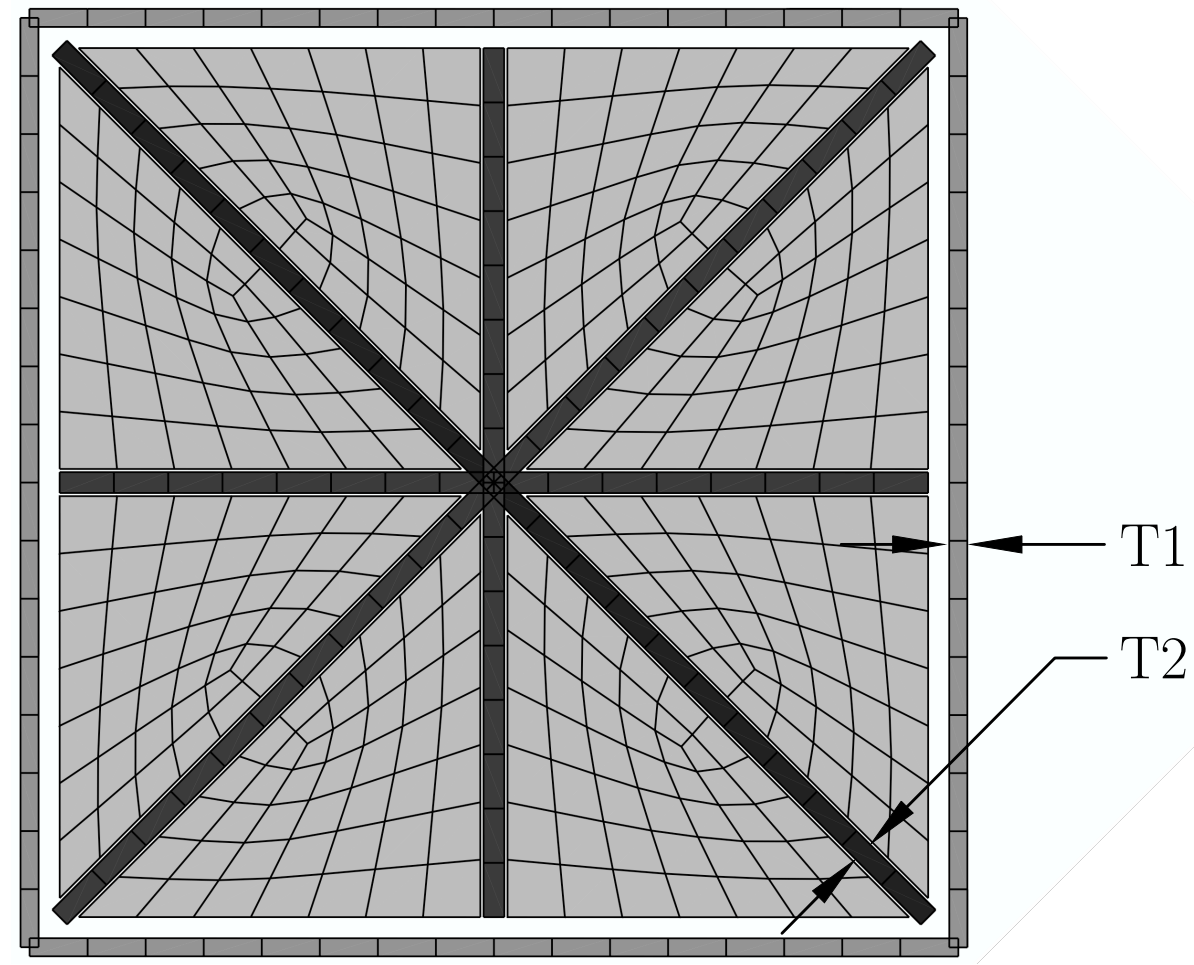

Figure 5: Top view of meshed specimen.

Brar et al. [46] for the AA7075-T6 alloy. However, the tested specimen was obtained from an used aircraft [40], offering reduced values for the elastic and plastic parameters due to damage and fatigue, as recommended by Fasanella and Jackson [47]. The values used for the Johnson-Cook plasticity models are listed in table 1, as well as a graphic representation of their true stress-strain behaviour for $\dot{\varepsilon}=0.01$ in figure 6 .

\begin{tabular}{llrr}
\hline \multicolumn{2}{c}{ Parameter } & AA2024-T3 & AA7075-T6 \\
\hline \multirow{2}{*}{ General } & $E(\mathrm{GPa})$ & 73.08 & 72.4 \\
properties & $v$ & 0.33 & 0.33 \\
& $\rho\left(\mathrm{kN} / \mathrm{m}^{3}\right)$ & 2.78 & 2.78 \\
\hline \multirow{4}{*}{ Plasticity } & $A(\mathrm{MPa})$ & 302 & 413 \\
model & $B(\mathrm{MPa})$ & 550 & 600 \\
& $C$ & 0.73 & 0.71 \\
& $\dot{\varepsilon_{0}}$ & $5 \times 10^{-4}$ & $1 \times 10^{-4}$ \\
\hline
\end{tabular}

Table 1: Material properties used for the AA2024-T3 [45] and AA7075-T6 [46] aluminium alloys and plasticity parameters for equation (1).

The hybrid energy absorption devices are made with three different materials. The outer tube is made from the AA2024-T3 aluminium alloy used in the fuselage skin panels, as it offers the necessary ductility required for progressive fold formation. Glassfibre-reinforced polyamide Ultramid A3WG10 BK00564 from BASF is used for the inner 


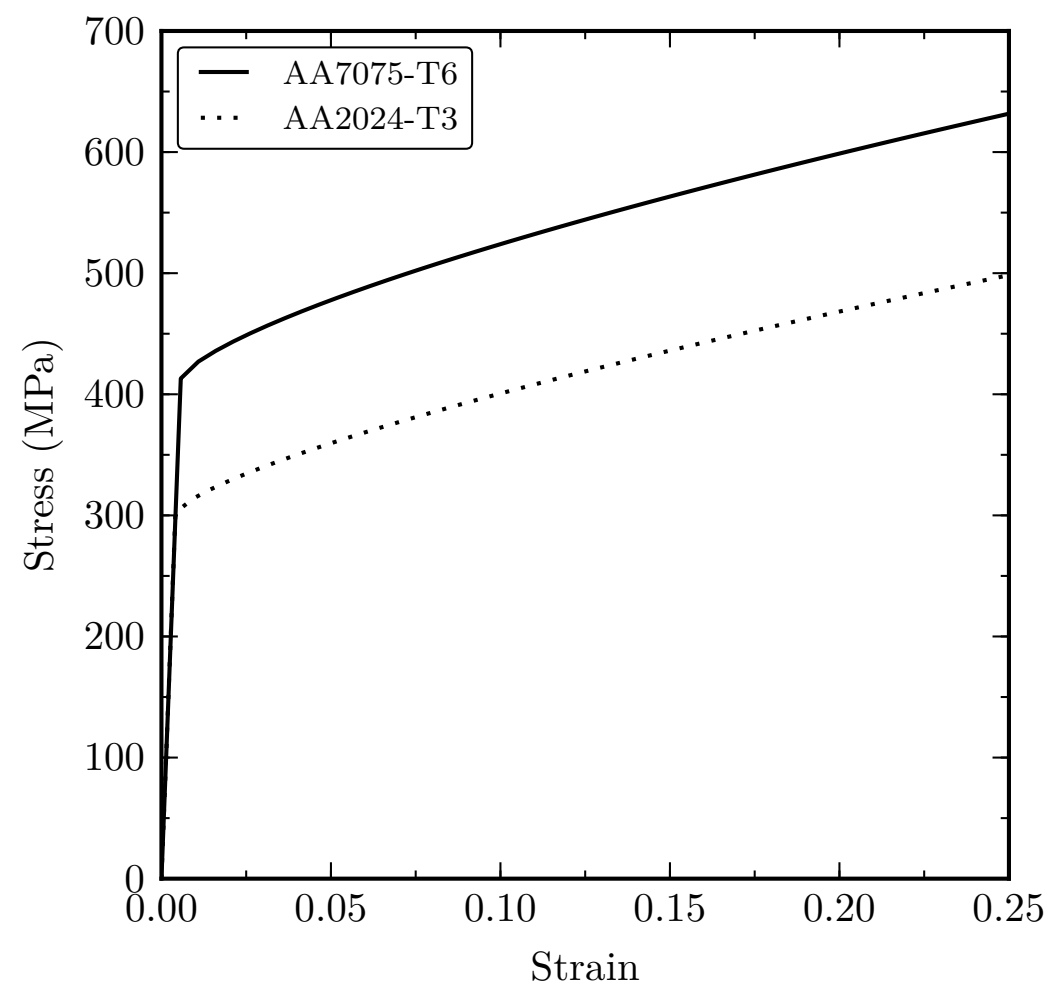

Figure 6: True stress-strain curves for the AA2024-T3 [45] and AA7075-T6 [46] alloys under a strain-rate of $\dot{\varepsilon}=0.01$.

plates and an Armacell polymeric foam (ArmaFORM PET/W AC 135) fills the void cells.

The GFRP's properties are obtained from the manufacturer [48]. A plasticity model with visco-elastic behaviour is used, with a maximum true strain before failure of $2.38 \%$. The following equation is used to adjust the material, with the parameters listed in equation (2) and table 2,

$$
\sigma_{\mathrm{y}}=\sigma_{0}+\left[\sum_{j=1}^{k} Q_{j}\left(1-e^{-b_{j} p}\right)\right]
$$

where $Q_{j}, b_{j}$, and $\sigma_{0}$ are material constants, and $k$ is the number of terms used to approximate the material's response, which for this material is $k=2$.

\begin{tabular}{cccccccc}
\hline$E$ & $v$ & $\rho$ & $\sigma_{0}$ & $Q_{1}$ & $Q_{2}$ & $b_{1}$ & $b_{2}$ \\
\hline $10.16 \mathrm{GPa}$ & 0.4 & $15.5 \mathrm{kN} / \mathrm{m}^{3}$ & $25 \mathrm{MPa}$ & $124.86 \mathrm{MPa}$ & $44.46 \mathrm{MPa}$ & 315.89 & 5748.46 \\
\hline
\end{tabular}

Table 2: Material properties of Ultramid A3WG10 BK00564 [48].

The data for adjusting the foam's response is obtained from compressive load testing [42], and the properties used to model this material are listed in table 3. The isotropic foam hardening model proposed by Deshpande and Fleck [49] is used to model the foam's behaviour. This model includes a pressure-dependent yield surface $f$ modelled by a von 
Mises circle in the deviatoric stress plane and an ellipse centred in the meridional stress plane. In order to represent the non-associated flow, a flow potential $g$ is also added to the model (see figure 7).

$$
f=\sqrt{\sigma_{\mathrm{eq}}^{2}+\alpha^{2} \sigma_{\mathrm{H}}^{2}}-D=0
$$

where $\sigma_{\text {eq }}$ is the von Mises equivalent stress, $\sigma_{\mathrm{H}}$ is the hydrostatic stress, $\alpha$ is the shape factor of the yield ellipse that defines the relative magnitude of the axis, and $D$ is the vertical axis of the yield ellipse. Furthermore, the following flow potential is used to represent non-associated flow,

$$
g=\sqrt{\sigma_{\mathrm{eq}}^{2}+\beta^{2} \sigma_{\mathrm{H}}^{2}}=0
$$

where $\beta$ represents the shape of the flow potential ellipse on the meridional stress plane, dependent on the plastic Poisson's ratio $v_{\mathrm{p}}$. Figure 7 shows the crushable foam constitutive model with isotropic hardening along the meridional plane.

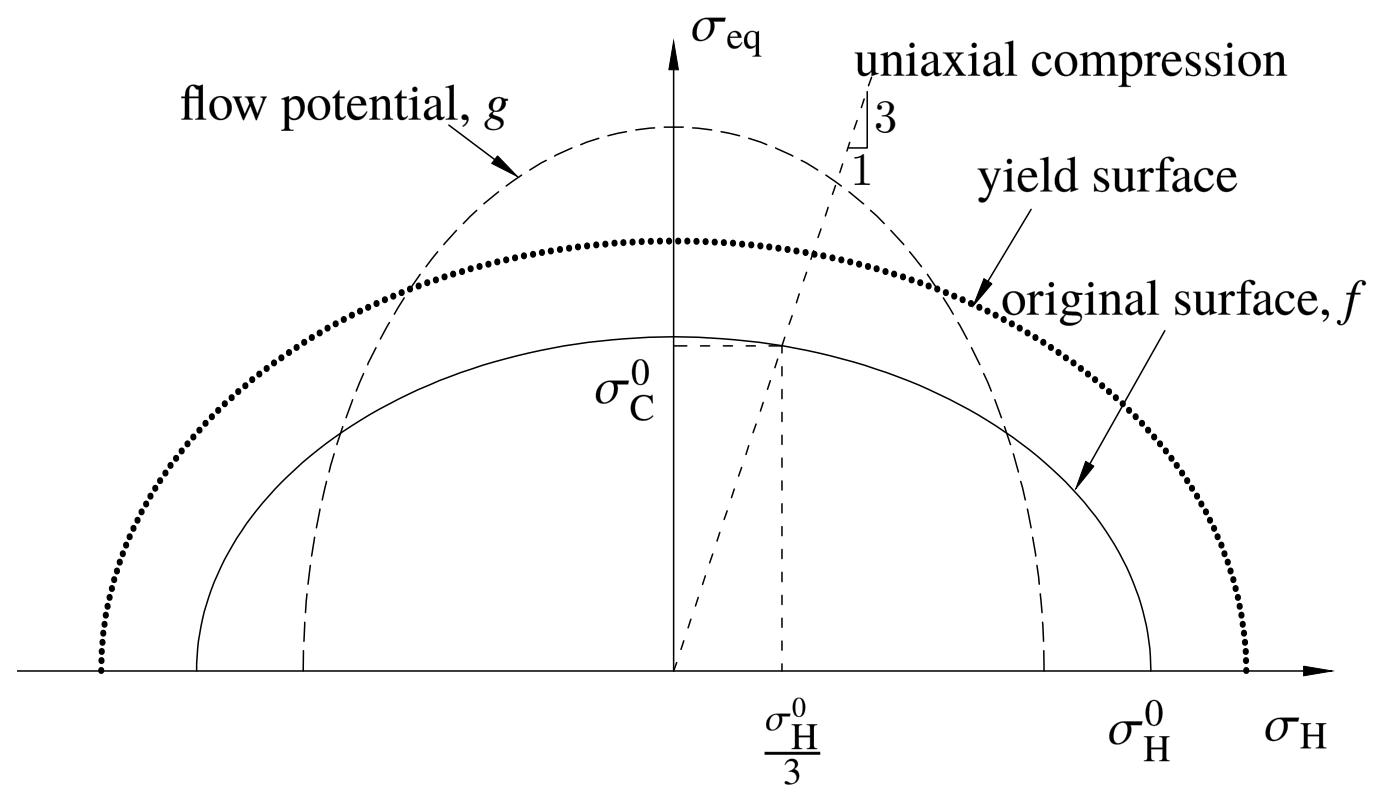

Figure 7: Yield surface and flow potential in the meridional plane for the crushable foam model with isotropic hardening. Adapted from [50].

\begin{tabular}{cccccc}
\hline$E$ & $v$ & $\rho$ & $\alpha$ & $\beta$ & $\nu_{\mathrm{p}}$ \\
\hline $59.01 \mathrm{MPa}$ & 0.1 & $1.35 \mathrm{kN} / \mathrm{m}^{3}$ & 0.729 & 1.76 & 0.111 \\
\hline
\end{tabular}

Table 3: Material properties of ArmaFORM PET/W AC 135 [42]. 


\subsection{Numerical simulation}

The fuselage section and energy absorbers were developed using the Abaqus CAE version 6.16. Shell elements were used to model the skin and floor, frames and underfloor beams for a more accurate behaviour of the model. The Omega-section longitudinal stringers are computed as beam elements in order to reduce the number of nodes and computing times, with no significant effect on the results. The passenger-seat blocks are approximated with evenly distributed point masses. A more detailed description of the model can be found in Paz et al. [36].

This specimen is enhanced by adding four ${ }^{5}$ vertical struts evenly spaced every $2 \mathrm{~m}$ along the longitudinal direction and $2.04 \mathrm{~m}$ on the transverse direction, ensuring the necessary area for standard aircraft cargo containers [51] as shown in figure 8. The latter also displays the two data extraction points, whose designation is inherited from the work in [36]. For this investigation, only two of the initial four points are used, locations $\mathbf{1}$ and $\mathbf{1 b}$, as they correspond with one of the original validation points and the location of one of the HEAs respectively.

Since material properties influence the correct mesh size, different values are taken for each component. A sensitivity analysis was performed, in which accurate behaviour of the absorber and computational time were considered. Relying on the mesh sensitivity results from Paz et al. [39], the tube and GFRP are modelled with shell elements $4 \mathrm{~mm}$ in length with 4 nodes and reduced integration; while the foam is meshed by solid 8-node elements with reduced integration, with an average edge length of $5 \mathrm{~mm}$, and distortion and enhanced hourglass controls to ensure convergence (see figures 2 and 5).

\subsection{Surrogate-based optimisation}

The initial hybrid absorber designs constitute the baseline model. However, even if it betters the original response from the fuselage section, changes in certain design characteristics could further improve the baseline design. In this research, surrogate-based optimisation techniques are applied to the hybrid absorber's design to improve different crashworthiness metrics.

\footnotetext{
${ }^{5}$ Only four absorbers are fitted, as the central fuselage station coincides with cargo door structures that interfere with the attaching of the device. The strut opposite to the cargo door is also removed to preserve symmetry.
} 


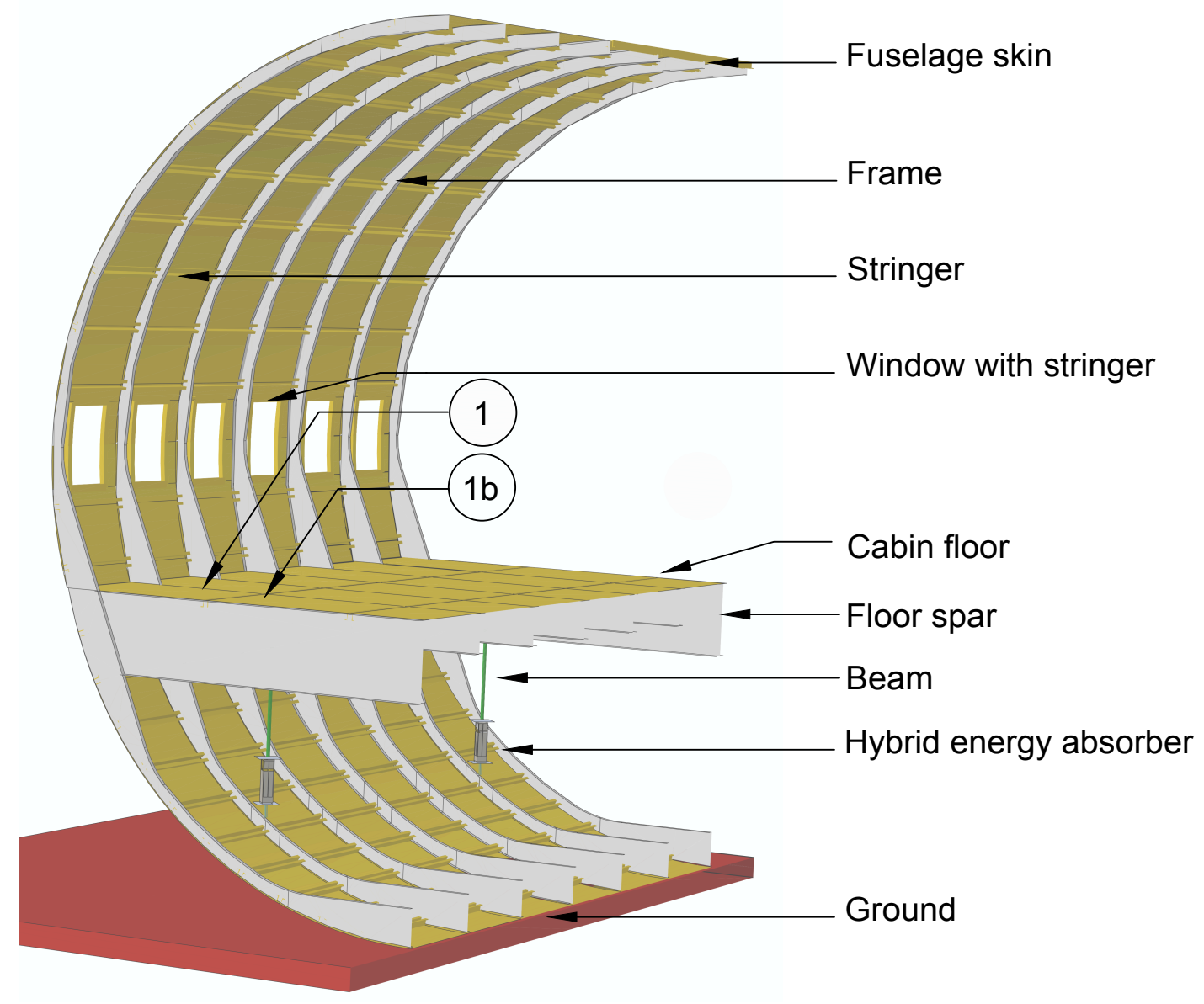

Figure 8: Numerical model in Abaqus CAE version 6.16. 


\subsubsection{Design variables and objective functions}

In any optimisation process, the design variables and objective functions must be established in the early stages. In the aforementioned model, all design variables affect the hybrid energy absorber's design. The tube has variable edge length (E) and material thickness (T1), the GFRP plates can also vary in thickness (T2), and the inner core can be constructed with different heights $(\mathrm{H})$ since slightly shorter reinforcement helps avoiding high initial peak forces [35]. These variables, upper and lower bounds, and initial design values are listed in table 4.

\begin{tabular}{llrrr}
\hline & & \multicolumn{2}{c}{ Bounds } & \\
\cline { 3 - 4 } Part & Variable & Lower & Upper & Initial Value \\
\hline \multirow{2}{*}{ Tube } & T1 & 1.20 & 2.50 & 1.50 \\
& $\mathrm{E}$ & 40.00 & 80.00 & 55.00 \\
\hline \multirow{2}{*}{ Core } & T2 & 1.00 & 3.00 & 1.50 \\
& $\mathrm{H}$ & 150.0 & 190.0 & 180.0 \\
\hline
\end{tabular}

Table 4: Bounds and initial values of design variables. All dimensions in millimetres.

As for the objective metrics, four are also chosen. Vertical acceleration trends are extracted from two locations on the cabin floor and filtered with a $48-\mathrm{Hz}$ four-pole Butterworth low-pass filter forwards and backwards as performed by Fasanella and Jackson [40]. For this investigation, only two of the initial four points are used, locations $\mathbf{1}$ and $\mathbf{1 b}$, as they correspond with one of the original validation points and the location of one of the HEAs respectively (see figure 8). The peak acceleration at the data extraction point $\mathbf{1}$ is identified by $A_{1}{ }^{\max }$, while the peak acceleration at location $\mathbf{1 b}$ is denoted as $A_{1 \mathrm{~b}}{ }^{\text {max }}$. Moreover, during the aforementioned previous phases of the investigation, a predominantly conflicting nature between the acceleration trends at both locations was perceived. The authors observations are that since one acceleration is measured directly over the HEA location, larger and stiffer HEAs lead to high peak acceleration values on this location due to higher triggering forces to initiate the post-buckling deformation state on the outer tube. However, larger designs perform better on the other measured location, as they offer better acceleration attenuation during the collapse process.

Moreover, an integration of the acceleration loads over the simulation time, denoted by $A_{1}{ }^{\text {avg }}$, is done for the evaluation of injury criteria on an Eiband diagram for headward accelerations including voluntary human and involuntary animal data [52]. The smaller the area under this curve, the safer the occupants are, thus being selected as another ob- 
jective metric. Given the important role of weight reduction in the aircraft industry, the mass of the hybrid energy absorber is taken into account, constituting the fourth and last monitored response.

\subsubsection{Sampling strategy}

To perform optimisation in this simulation, traditional methods are discarded due to the problems that arise in such a non-linear problem. To address this, surrogate-based optimisation is chosen, given its robustness and efficiency. First, once the model with hybrid energy absorbers is parametrised, a Latin Hypercube sampling (LHS) strategy is used over the design space. Using the Dakota software [53] as a sampling generator, a total of 600 numerical simulations were computed parallelised with the domain scheme on 16-node CPUs. Considering the amount of simulations to be computed, every time-saving strategy is deemed vital for efficient sampling execution. The numerical model and output databases are lightened, limiting high-frequency outputs to a few nodes. Generic variables such as stresses or strains are requested every millisecond of the $100 \mathrm{~ms}$ simulation, while accelerations at the monitored nodes are extracted every $0.1 \mathrm{~ms}$. Although using massscaling is discarded given the effect of inertias in the simulation, subcycling techniques are employed on the smaller elements from the hybrid absorbers. By using this method, the original stable time increment $\Delta t_{\text {fus }}=1.29 \mu \mathrm{s}$ is not hindered by the increment required for the absorbers, $\Delta t_{\mathrm{HEA}}=0.36 \mu \mathrm{s}$, leading to an average time saving of over $27 \%$ (10 hours) per simulation. All samples are divided into 15 domains using the Abaqus parallelisation scheme and computed on 20 CPUs from a high performance computing (HPC) cluster with a theoretical peak performance of 7.6 TFLOPS; yielding a computational sampling time of approximately 26 natural days.

\subsubsection{Surrogate model and optimisation}

After the sampling is completed, the surrogate model can be constructed. Several methods exist, although the moving least squares technique with second order base functions was selected given its performance in previous investigations. In order to judge the model's fitness, the $R^{2}$ and root mean squared error (RMSE) indicators are looked into. However, the predictive capabilities of the model also need assessing. For this, the RMSE is also computed using a 10 -fold cross validation strategy.

Once a reliable and trustworthy surrogate model is obtained, optimisation can be performed. Using algorithms with a need for derivative or gradient information is discarded, 
as local minima could lead to misleading results. Genetic algorithms, however, have delivered outstanding results in surrogate-based optimisation

Two genetic algorithms are used for the optimisation task: a single-objective genetic algorithm (SOGA) and a multi-objective genetic algorithm (MOGA), both from the JEGA library [54]. While the results obtained from the SOGA are one single point, the MOGA provides a set of points, the Pareto frontier, which represents a trade-off between the functions considered. The parameters chosen for the genetic algorithms which yielded the best converge and results are listed in table 5.

\begin{tabular}{lr}
\hline Parameter & Value \\
\hline Maximum population size & 750 \\
Offset normal mutation rate & 0.5 \\
Two-point crossover probability & 0.7 \\
Elitism & 100 \\
Maximum allowed individuals & $10^{6}$ \\
\hline
\end{tabular}

Table 5: Configuration parameters for the JEGA library optimisation algorithms.

Once the different optima are obtained, each one is again computed to assess whether the surrogate-based optimisation produced reliable results.

\section{Results}

\subsection{Surrogate model fitness}

Checking the fitness of the surrogate model approximation is essential for obtaining accurate results in the optimisation. Different order polynomial functions are trialled, with third order yielding the best approximation. Table 6 shows the $R^{2}$ and RMSE values for the MLS surrogate for each of the objective functions.

\begin{tabular}{lrrr}
\hline & \multicolumn{3}{c}{ Metrics } \\
\cline { 2 - 4 } Obj. function & $R^{2}$ & RMSE & RMSE $\left({\left.\mathrm{C}-\mathrm{V}^{*}\right)}\right.$ \\
\hline$A_{1}{ }^{\max }$ & 0.916 & $2.54 \mathrm{~g}$ & $4.10 \mathrm{~g}$ \\
$A_{1 \mathrm{~b}}{ }^{\max }$ & 0.939 & $1.52 \mathrm{~g}$ & $2.96 \mathrm{~g}$ \\
$A_{1}{ }^{\mathrm{avg}}$ & 0.923 & $1.09 \mathrm{~g}$ & $1.59 \mathrm{~g}$ \\
Mass & 0.996 & $2.01 \times 10^{-4} \mathrm{~kg}$ & $9.29 \times 10^{-4} \mathrm{~kg}$ \\
\hline
\end{tabular}

Table 6: MLS surrogate model fitness. $\mathrm{C}-\mathrm{V}^{*}$ refers to the cross-validation value of RMSE. 
The $R^{2}$ indicator is equal or higher than 0.9 for all functions, with also providing RMSE values lower than $10 \%$ of typical values for the noisier metric, $A_{1}{ }^{\text {max }}$. The RMSE is also evaluated with the 10 -fold cross validation strategy, with values less than $50 \%$ higher than the original error. The surrogate approximation is considered valid for the optimisation process.

\subsection{Baseline model}

As a first approach, the baseline model is analysed. Results show a significant improvement on the peak acceleration values at both locations (shown in table 7). When studying the post-test deformation of the absorber in figure 9 however, it only shows one complete fold, hinting that the baseline design is slightly stiffer than desired. Therefore, the bounds from table 4 were set tending towards values that reduced the axial stiffness of the specimen. Figure 9 also reveals how the foam extrusions recover the elastic deformation after the fuselage rebound phase as the absorber's crushing plates moderately separate.

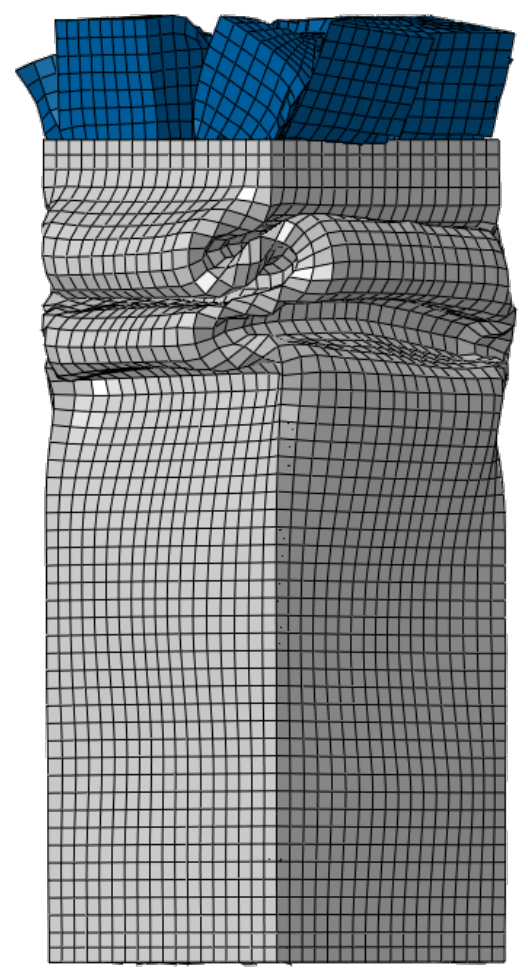

Figure 9: Post-impact deformation of HEA under location $\mathbf{1 b}$ for the baseline design.

\subsection{Single-objective optimisation}

Unconstrained and constrained single-objective optimisation is performed using a genetic algorithm. This process is performed over the surrogate model, hence computational 
times ranged between 3 to 6 minutes, mainly depending on the number of individuals needed for convergence. A reasonable set of initial design variables is assigned to a baseline model, which gives insight on the specimen's effect on the fuselage and serves as a measure for the optimisation contributions.

Moreover, in order to further check the accuracy of the results delivered by the optimisation algorithm, all results presented for the optimisation processes correspond to re-run simulations with the assigned design variables yielded from the optimisation. Although minor discrepancies are observed between the objective functions provided by the optimisation algorithm and the numerical simulation, mismatches were under $7 \%$ for all objective metrics, a values expected given the compliance observed between the surrogate model and the simulation shown in table 6 .

Starting with the $A_{1 \mathrm{~b}}{ }^{\max }$ as an objective function, optimisation is applied. Results show that the metric is indeed optimised, reducing the peak acceleration by over $50 \%$ when compared to the original fuselage and $44 \%$ with respect to the baseline model. This is achieved, however, by selecting an absorber with a low stiffness, as the aluminium thickness and the absorber's edge tend to the lower bounds, with the consequent low mass value (table 7). This leads to an excellent acceleration reduction at location $\mathbf{1 b}$, while peak values at location 1 are only improved by $40 \%$ as no boundary was defined.

As a means to repress excessive accelerations and heavy specimens, the optimisation is again computed with constraints for $A_{1}{ }^{\max }$ and the specimen's mass. The acceleration peak is limited to $35 \mathrm{~g}$ as it is deemed sufficient to obtain injury criteria in the moderate injury region for the Eiband diagram [52], whereas the mass is to be kept under $0.5 \mathrm{~kg}$ for efficiency purposes. Thus, the problem is now formulated as

$$
\min \left(A_{1 \mathrm{~b}}^{\max }\right)
$$

while enforcing

$$
\begin{aligned}
& \text { mass } \leqslant 0.50 \mathrm{~kg} \\
& A_{1}{ }^{\max } \leqslant 35.00 \mathrm{~g}
\end{aligned}
$$

When both constraints are activated, results are more sensible and practical than the previous. The strut's edge and inner core height stay close to the lower boundary, given their effect on the initial peak acceleration when the absorber crushing initiates. In turn, 


\begin{tabular}{|c|c|c|c|c|c|c|c|}
\hline \multirow{2}{*}{ Sample } & \multicolumn{4}{|c|}{ Variables (mm) } & \multicolumn{3}{|c|}{ Responses } \\
\hline & $\mathrm{T} 1$ & $\mathrm{E}$ & $\mathrm{T} 2$ & $\mathrm{H}$ & $A_{1 \mathrm{~b}}^{\max }$ & $A_{1}^{\max }$ & Mass \\
\hline Original fuselage & - & - & - & - & $87.25 \mathrm{~g}$ & $81.52 \mathrm{~g}$ & - \\
\hline Baseline & 1.50 & 55.00 & 1.50 & 180.0 & $58.21 \mathrm{~g}$ & $43.21 \mathrm{~g}$ & $0.34 \mathrm{~kg}$ \\
\hline Unconstrained & 1.59 & 46.00 & 2.78 & 183.0 & $24.12 \mathrm{~g}$ & $45.20 \mathrm{~g}$ & $0.35 \mathrm{~kg}$ \\
\hline Constrained & 2.04 & 62.10 & 1.82 & 181.1 & $24.70 \mathrm{~g}$ & $34.64 \mathrm{~g}$ & $0.49 \mathrm{~kg}$ \\
\hline
\end{tabular}

Table 7: Design variables and response metrics of original fuselage without absorbers, with baseline absorbers, and with the single-objective optimum specimen designs.

both thicknesses are increased, yielding a design with more energy absorption capabilities. Thus, both constraints are fulfilled, and the acceleration at location $\mathbf{1 b}$ is still improved by $21 \%$ with respect to the baseline design. Design values and the responses obtained for the baseline and optima have been tabulated in table 7.

The acceleration trends at location $\mathbf{1}$ are shown in figure 10. The constrained optimum not only shows lower acceleration peaks, but also values which do not exceed $25 g$ for most of the simulation. That, in turn, is translated into lower injury levels, as shown in the Eiband diagrams from figures 11a and 11b. Moreover, the area under the passenger floor is less compromised in the enhanced fuselage, an important factor not only for passenger safety but also when transporting hazardous and valuable cargo. In the end, the post-test distance to the ground at location 1, previously $0.61 \mathrm{~m}$, is increased to $1.03 \mathrm{~m}(68 \%)$ in the constrained optimum, as shown in figures $12 \mathrm{a}$ to $12 \mathrm{~d}$. The rise of the hinge formed on the lower left area (circled in figure 12b) is also constrained by the struts, reducing the risk of impact with the passenger floor and avoiding the resulting peak seen in figure 10 .

\subsection{Multi-objective optimisation}

Single-objective optimisation, as expected, improves the original and baseline designs, especially when other constraints are enforced. However, if optimality is sought on two or more metrics, multi-objective optimisation is used. Here, two procedures are presented, one with two objective functions and another with all four metrics. First, the absorber is optimised for minimum acceleration peaks at two locations. Results are expressed as a Pareto front, which has been detailed in table 8 .

A deeper look at the Pareto values from figure 13 shows that the values of $A_{1}{ }^{\text {max }}$ are the same order of magnitude but higher than those at $A_{1 \mathrm{~b}}{ }^{\max }$, as expected from previous investigations [55]. This could be caused by the load distribution during the initial crushing states, where the main frames absorb most of the kinetic energy. Thus, when a data extraction location is closer to the frame, acceleration peaks tend to be higher. 


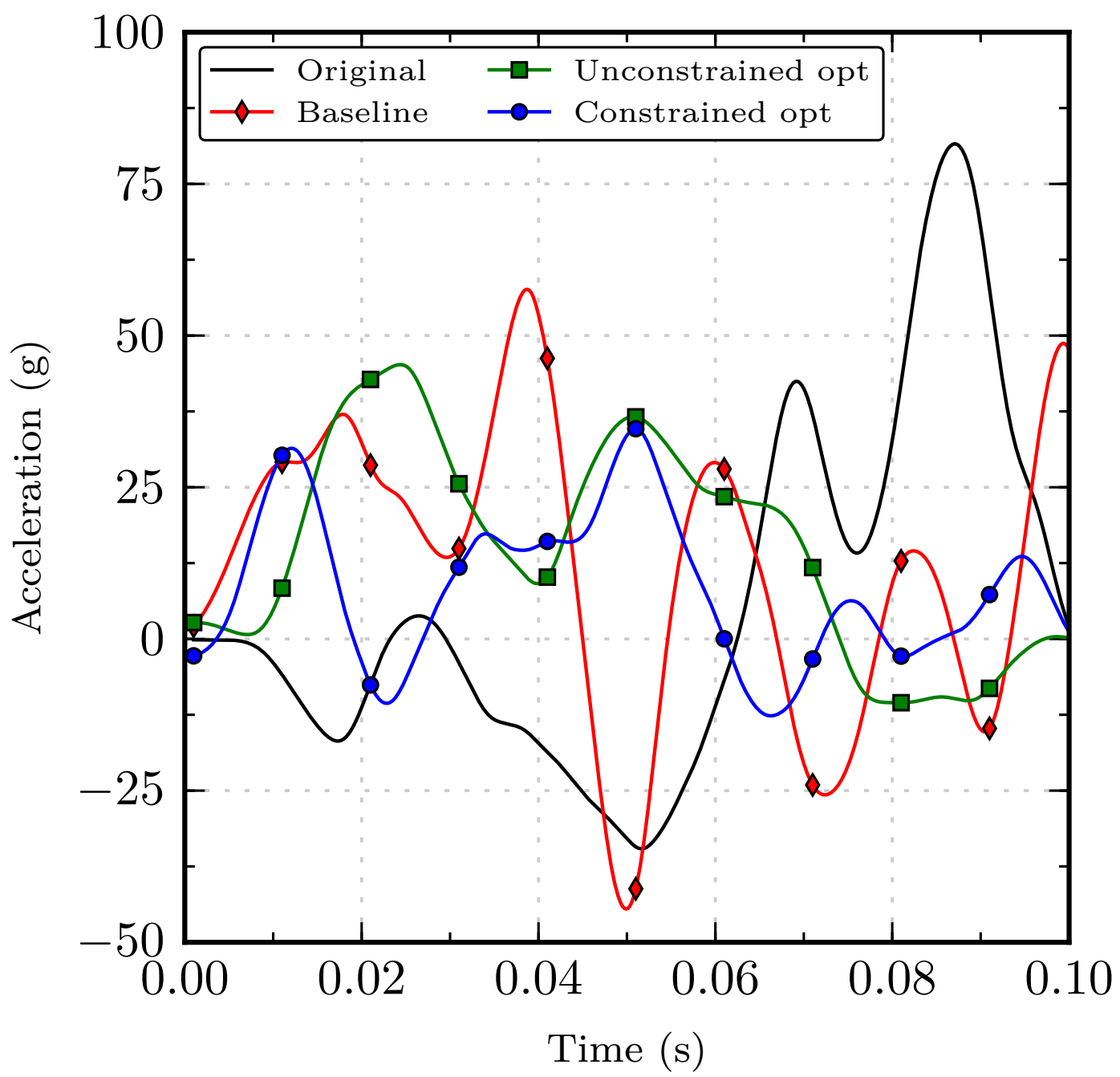

Figure 10: Vertical acceleration history of original, baseline and optimum models at location 1.

The response from location $\mathbf{1 b}$ is lessened by the absorber, which not only dissipates kinetic energy but also avoids vibration of the passenger floor structures. Looking at the variables and metrics evolution in table 8, the thickness of the GFRP tends to the low boundary value, as thin plates are sufficient to enable the interaction effect between all three components given the high density and stiffness of the composite. Also, the tube's edge tends to be kept on the lower half of the design space (under $65 \mathrm{~mm}$ ), as surpassing that value would entail higher masses and peak loads resulting from absorbers being too rigid. Moreover, the discordances between the results supplied by the genetic algorithm and the FEA were measured as a last assessment of the surrogate-based optimisation procedure. Results show discrepancies under $7 \%$ for the acceleration-related metrics (shown in tables 8 and 9) and less than $1 \%$ for the mass.

As a last approach, unconstrained optimisation with all four metrics is performed. Rather than requesting a Pareto frontier, the closest specimen to the utopia point, called 


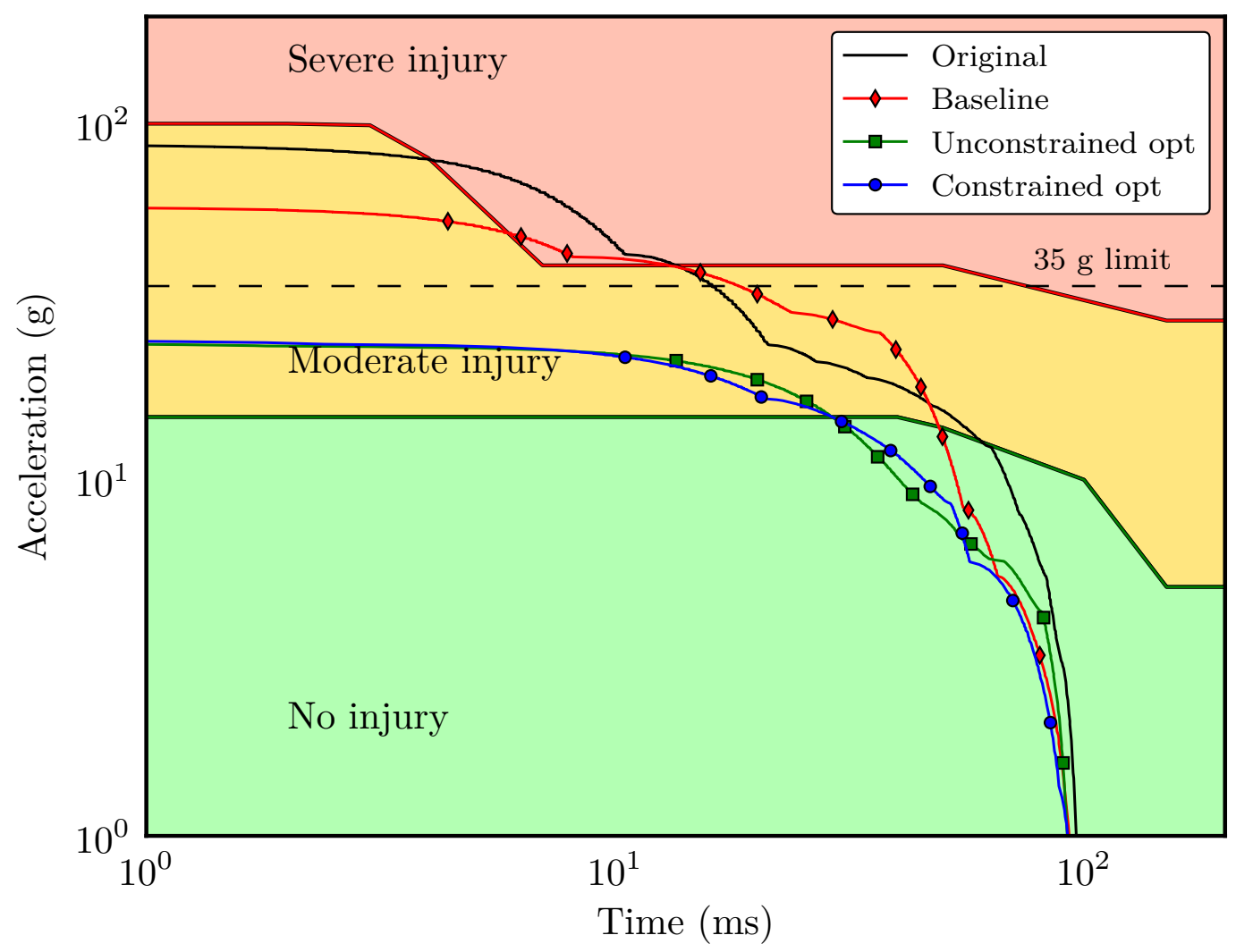

(a) Headward Eiband injury criteria at location $\mathbf{1}$.

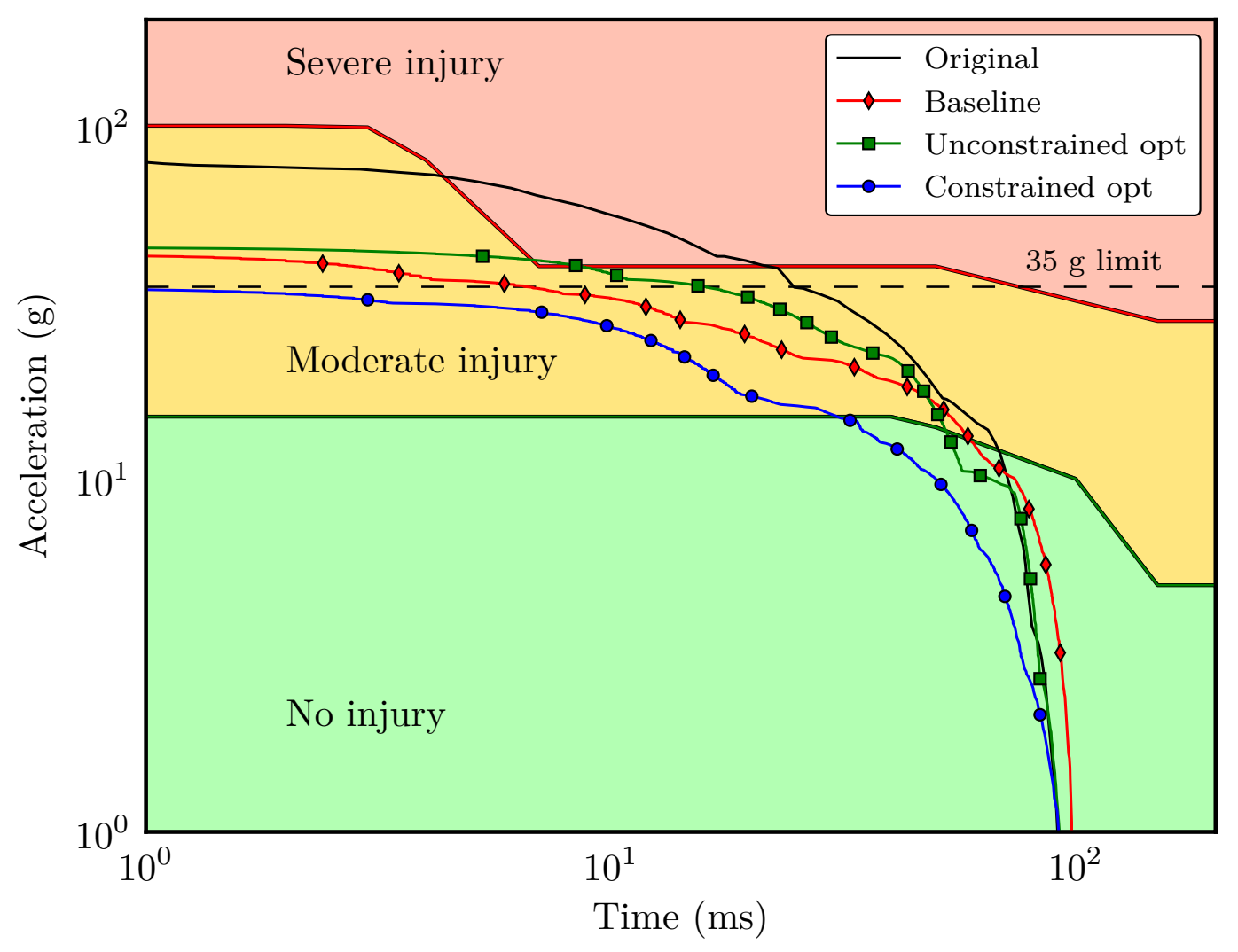

(b) Headward Eiband injury criteria at location $\mathbf{1 b}$.

Figure 11: Headward Eiband diagrams for vertical accelerations at locations $\mathbf{1}$ and $\mathbf{1 b .}$ 


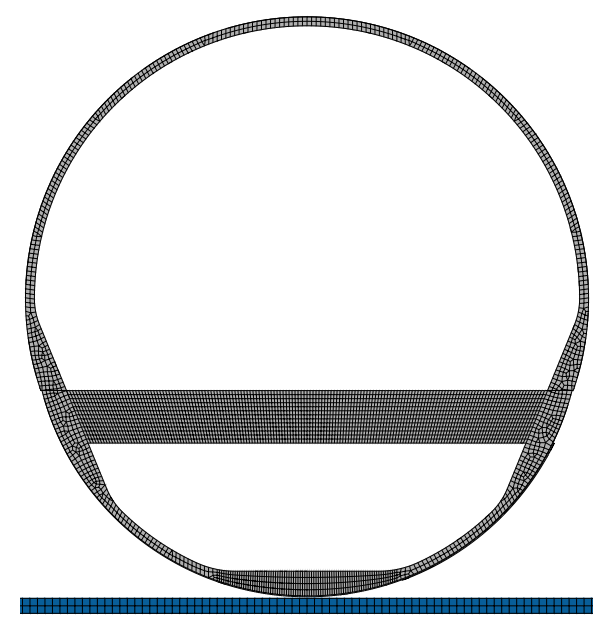

(a) Original fuselage section. Pretest numerical model.

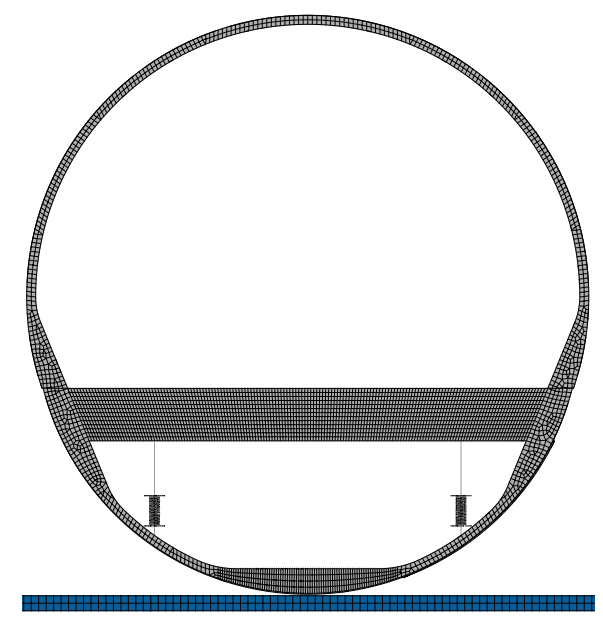

(c) Fuselage section with HEAs. Pretest numerical model.

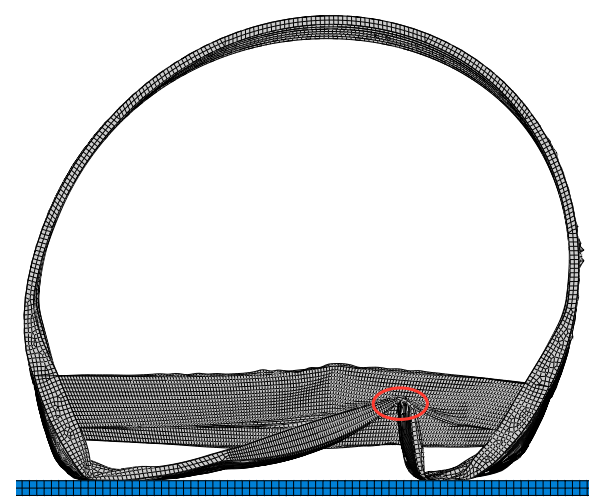

(b) Original fuselage section after hardlanding scenario. $\left(^{*}\right)$

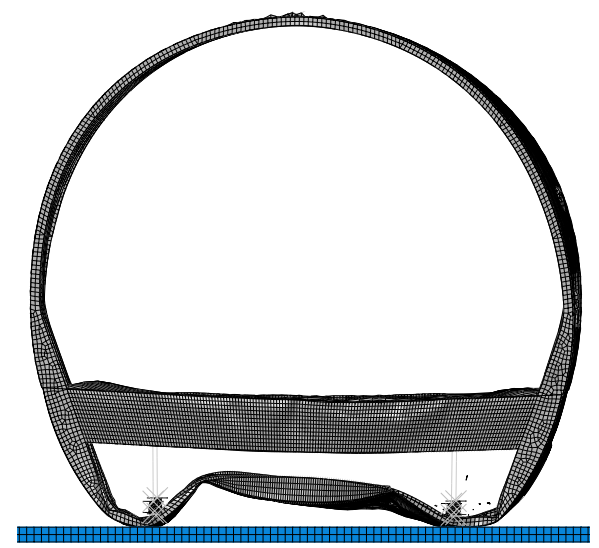

(d) Fuselage section with HEAs after hard-landing scenario.

Figure 12: Pretest and post-test comparison after $100 \mathrm{~ms}$ of simulation of fuselage section with and without HEAs. $\left(^{*}\right)$ Impact of sub-floor structures with passenger floor beams circled in red in figure $12 \mathrm{~b}$.

\begin{tabular}{cccccrrrr}
\hline \multicolumn{4}{c}{ Variables $(\mathrm{mm})$} & & \multicolumn{3}{c}{ Responses } \\
\cline { 1 - 2 } \cline { 6 - 7 } T1 & $\mathrm{E}$ & $\mathrm{T} 2$ & $\mathrm{H}$ & & $A_{1 \mathrm{~b}}{ }^{\max }(\mathrm{g})$ & $A_{1}{ }^{\max }(\mathrm{g})$ & Mass $(\mathrm{kg})$ \\
\hline 1.25 & 66.12 & 2.90 & 186.32 & & $40.07(+6.3 \%)$ & $23.12(-4.3 \%)$ & 0.51 \\
2.04 & 62.14 & 1.82 & 181.04 & & $34.65(+4.1 \%)$ & $24.58(-3.3 \%)$ & 0.49 \\
2.41 & 48.14 & 2.61 & 184.60 & & $24.77(-2.6 \%)$ & $24.93(+5.1 \%)$ & 0.45 \\
2.13 & 75.19 & 1.09 & 180.74 & & $16.01(-2.8 \%)$ & $25.24(+1.8 \%)$ & 0.57 \\
2.27 & 45.21 & 2.25 & 160.81 & & $14.94(+1.2 \%)$ & $26.85(-3.7 \%)$ & 0.37 \\
1.40 & 55.27 & 1.95 & 183.19 & & $13.85(-2.0 \%)$ & $30.26(+5.6 \%)$ & 0.36 \\
\hline
\end{tabular}

Table 8: Design variables and response metrics for two-objective optimisation procedure. Values in brackets correspond to the discrepancy between the numerical simulation with respect to the results from the optimisation. 


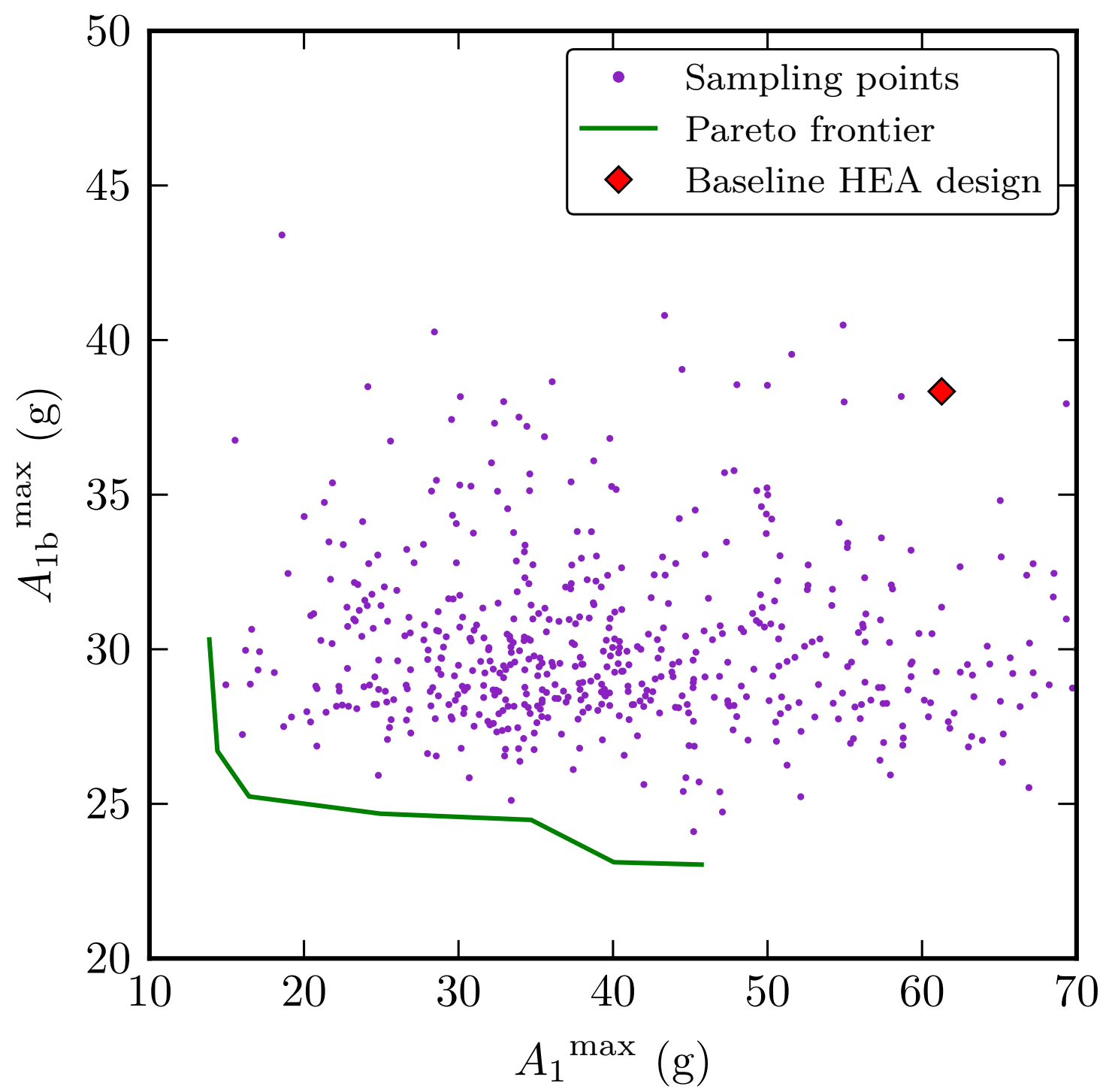

Figure 13: Pareto front and sampling values for $A_{1}{ }^{\max }$ and $A_{1 \mathrm{~b}}{ }^{\max }$.

the knee-point, is provided. The optimum has nearly matched acceleration peaks, both neighbouring the $25 \mathrm{~g}$ region. The overall reduction of the peak load is over $50 \%$ on both data extraction points when compared to the original fuselage section. Injury levels are reduced from severe to moderate at both locations, as shown by the Eiband diagram in figure 14. The injury curves from the optimum do not reach the severe injury region as opposed to the original, and enter the no injury area earlier. Moreover, mass is also kept under the $0.5 \mathrm{~kg}$ threshold. In addition, the cargo area is maintained, reducing the risk of sub-floor piercing through the passenger floor with the consequent occupant injury.

It should also be noted that results from the optimisation procedures reveal a peculiar behaviour on the acceleration trends for $A_{1}{ }^{\max }$ and $A_{1 \mathrm{~b}}{ }^{\max }$; showing a difference between the two of up to $45 \mathrm{~g}$. While the objective metrics derived from the optimisation closely resemble those in a finite element simulation with equal values for the design variables; 
there may be some inaccuracies in the fuselage model used. However, coupling between full-scale impact simulations and surrogate-based optimisation has been successfully performed, confirming itself as an outstanding tool in aircraft crashworthiness design.

\begin{tabular}{ccccccccc}
\hline \multicolumn{4}{c}{ Variables $(\mathrm{mm})$} & & \multicolumn{5}{c}{ Responses } \\
\cline { 1 - 3 } \cline { 6 - 8 } T1 & $\mathrm{E}$ & $\mathrm{T} 2$ & $\mathrm{H}$ & & $A_{1 \mathrm{~b}}{ }^{\max }$ & $A_{1}{ }^{\max }$ & Mass & $A_{1}{ }^{\text {avg }}$ \\
\hline 1.96 & 69.57 & 1.26 & 150.57 & & $24.36 \mathrm{~g}(+3.6 \%)$ & $25.20 \mathrm{~g}(+2.8 \%)$ & $0.48 \mathrm{~kg}$ & $10.71 \mathrm{~g}(-3.1 \%)$ \\
\hline
\end{tabular}

Table 9: Design variables and response metrics of the closest specimen to utopia point after four-objective unconstrained optimisation. Values in brackets correspond to the discrepancy between the numerical simulation with respect to the results from the optimisation.

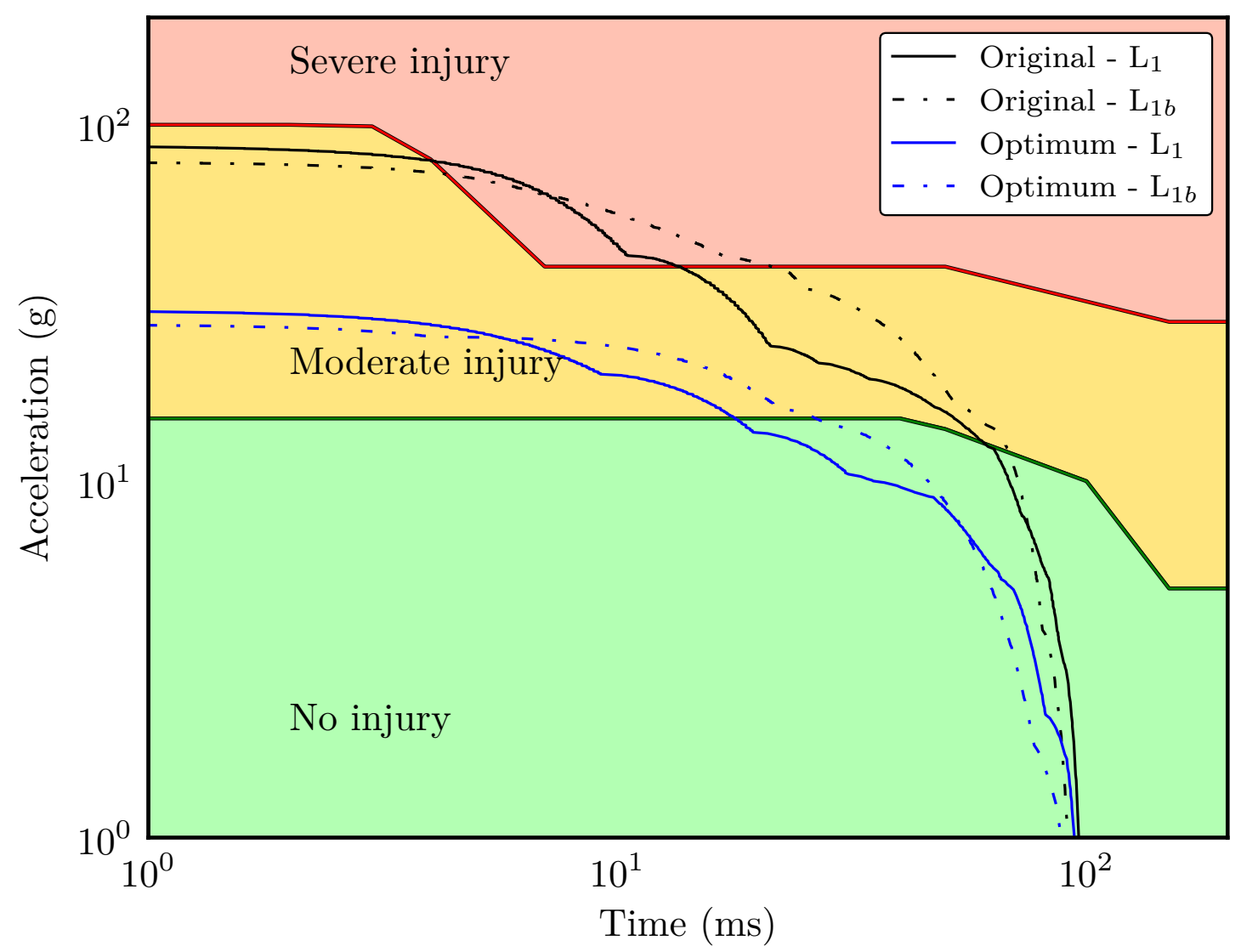

Figure 14: Headward Eiband injury criteria for vertical acceleration of original fuselage and HEA optimum from table 9 for four-objective optimisation.

In order to assess the performance of the hybrid absorbers during the simulation, the post-test deformation from figure 15, corresponding to the hybrid energy absorber under location $\mathbf{1 b}$ for the model closest to the utopia point, is analysed. In the full specimen from figure $15 \mathrm{a}$, the outer tube exhibits the formation of three complete plastic folds, corresponding to a crushing stroke of $60 \mathrm{~mm}$ with fold lengths close to $20 \mathrm{~mm}$. Considering that the crushing initiates from the upper end of the tube, the GFRP skeleton is primarily 


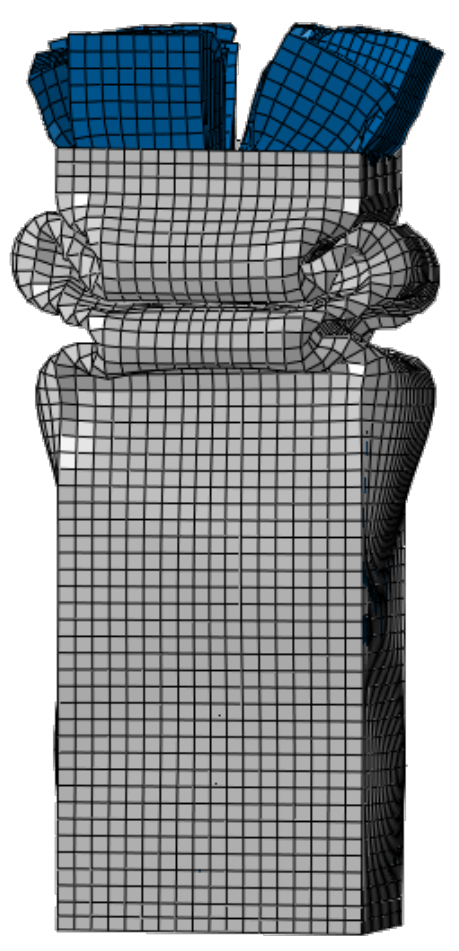

(a) Hybrid energy absorber.

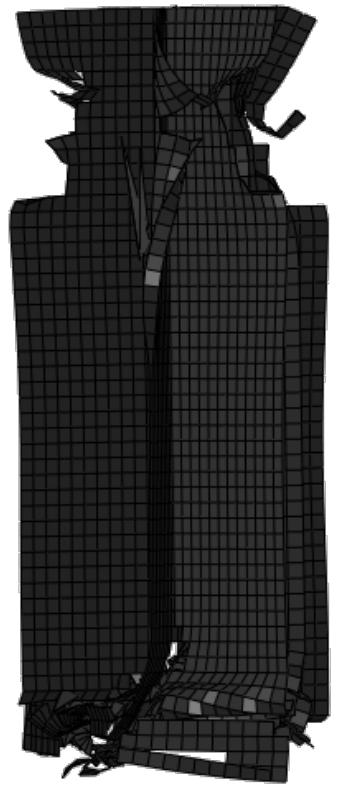

(b) Composite skeleton.

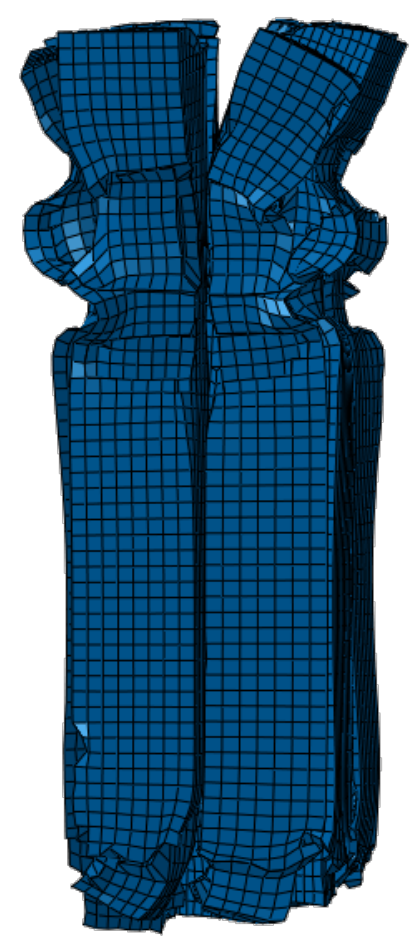

(c) Foam extrusions.

Figure 15: Post-test deformation of hybrid energy absorber under location $\mathbf{1 b}$ for closest model to utopia point (table 9). Complete specimen and inner core.

affected in the homologous region. Figure $15 \mathrm{~b}$ reveals significant damage on the lowest part of the structure, while the rest still maintains structural integrity for further energy absorption if required. Finally, figure $15 \mathrm{c}$ shows the foam extrusions after crushing and elastic strain recovery, almost reaching pre-test dimensions.

Nodal forces were extracted for the aforementioned absorber, and using the "free-body cut" tool from the Abaqus software, the force-displacement curve presented in figure 16 was extracted and later treated with a SAE 600 filter. The graph clearly reveals two sets of local maxima along the curve, the first nearly reaching $80 \mathrm{kN}$ while the others peak at $65 \mathrm{kN}$. These values correspond to the initial and secondary fold formations, with the latter $20 \%$ lower as is typical with this type of absorbers. The force plateau, however, observed $1 \mathrm{~cm}$ into the crushing process differs from what was expected from the results with the analysis of standalone absorbers. This plateau is due to the crushing required from the device as a feature of the fuselage, since at times no force is transmitted to the specimens. The total crushing length is circa $6 \mathrm{~cm}$, leading to a stroke efficiency (the ratio between the crushed length and the original dimension) of $S t_{\mathrm{e}} \approx 0.30$. Considering the stroke efficiency achieved by similar components $\left(S t_{\mathrm{e}}=0.8\right.$ in [39]), it is considered that more folds could have developed if the impact conditions were more severe. Still, the final internal energy ${ }^{6}$ dissipation from the absorbers is over $5 \%$ (approximately $8 \mathrm{~kJ}$ ) 


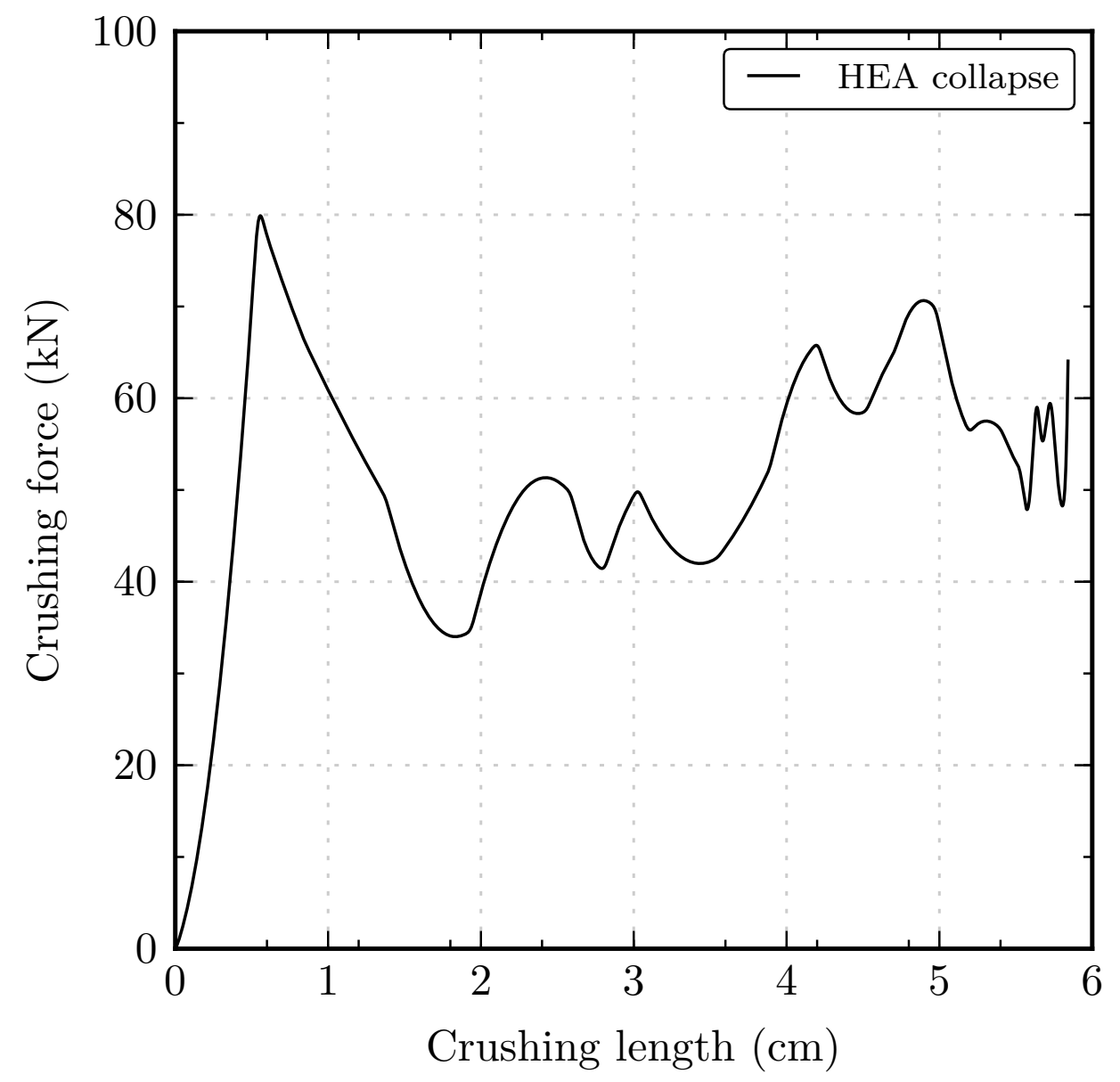

Figure 16: Force-displacement evolution of energy absorber under location $\mathbf{1 b}$ of the closest specimen to utopia point after four-objective unconstrained optimisation (see table 9). 
of that from the whole model, as shown in figure 17. This graph also reveals how their contribution is mainly relevant around $50 \mathrm{~ms}$ into the impact, where they undergo collapse after the triggering load is reached. Thus, the hybrid absorbers only collapse during $10 \%$ of the analysis time, maintaining structural integrity to provide support for frames and floor beams to avoid further cargo-area deformation.

An analysis of the HEA plastic dissipation trends is also performed and depicted in figure 18 as to determine the contribution from each of the components. The outer tubes are the main energy dissipating structures, responsible for absorbing over $6 \mathrm{~kJ}$ of the total $7.5 \mathrm{~kJ}$. The foam and GFRP structures dissipate less than $1 \mathrm{~kJ}$ each, as the former mainly deforms elastically and the latter's brittle nature leads to failure with low plastic deformation values. However, their presence is required to enable the progressive folding of the tube in the post-buckling stage, as this inner core reduces the fold length of the tube.

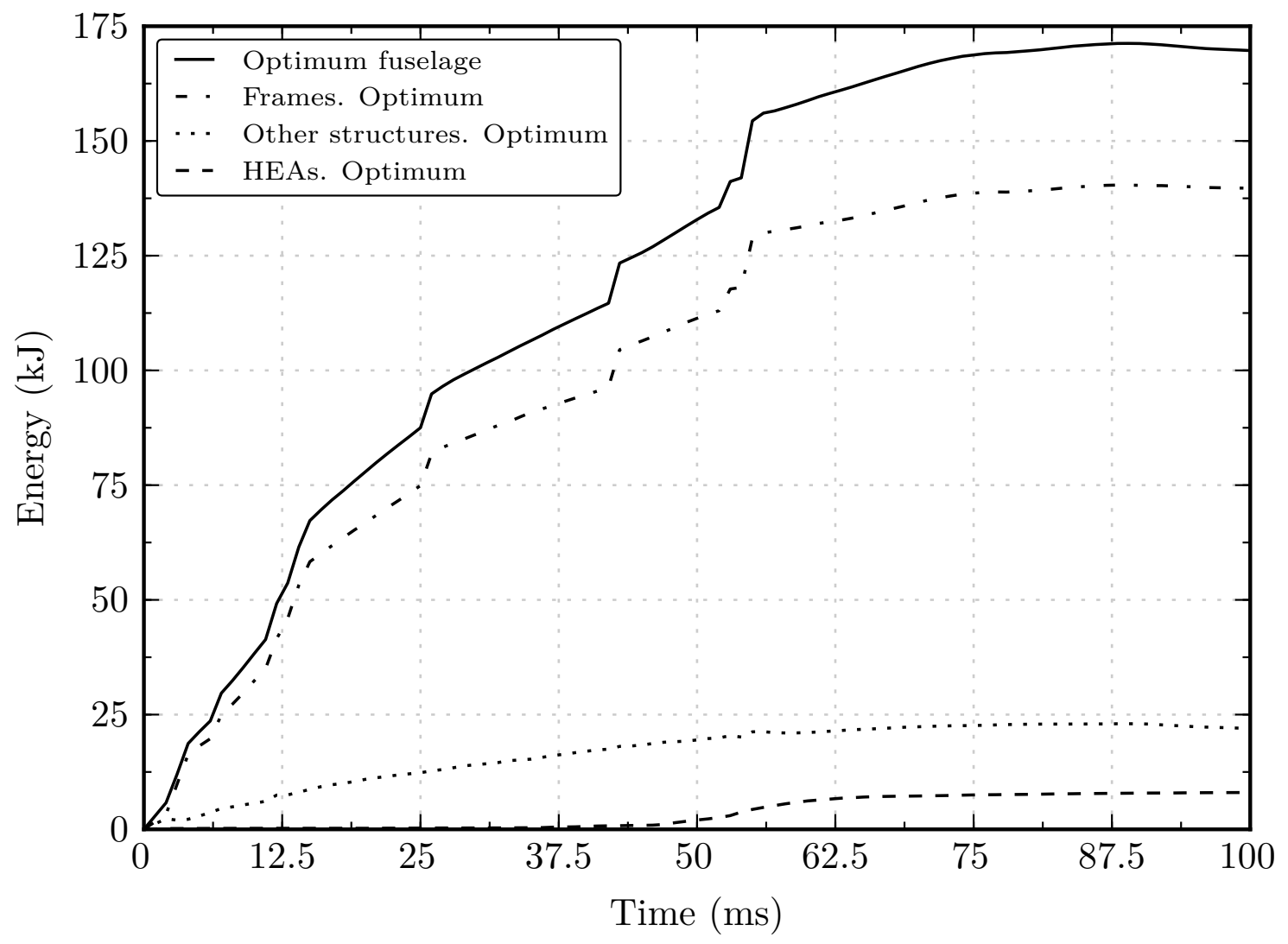

Figure 17: Internal energy for model in table 9 segregated according to structural components.

Exploiting the capabilities of numerical simulations over experimental procedures,

\footnotetext{
${ }^{6}$ Internal energy is computed in Abaqus as the sum of recoverable strain energy, plastic dissipation energy, energy dissipated by creep, viscoelasticity and swelling, and the artificial strain energy.
} 


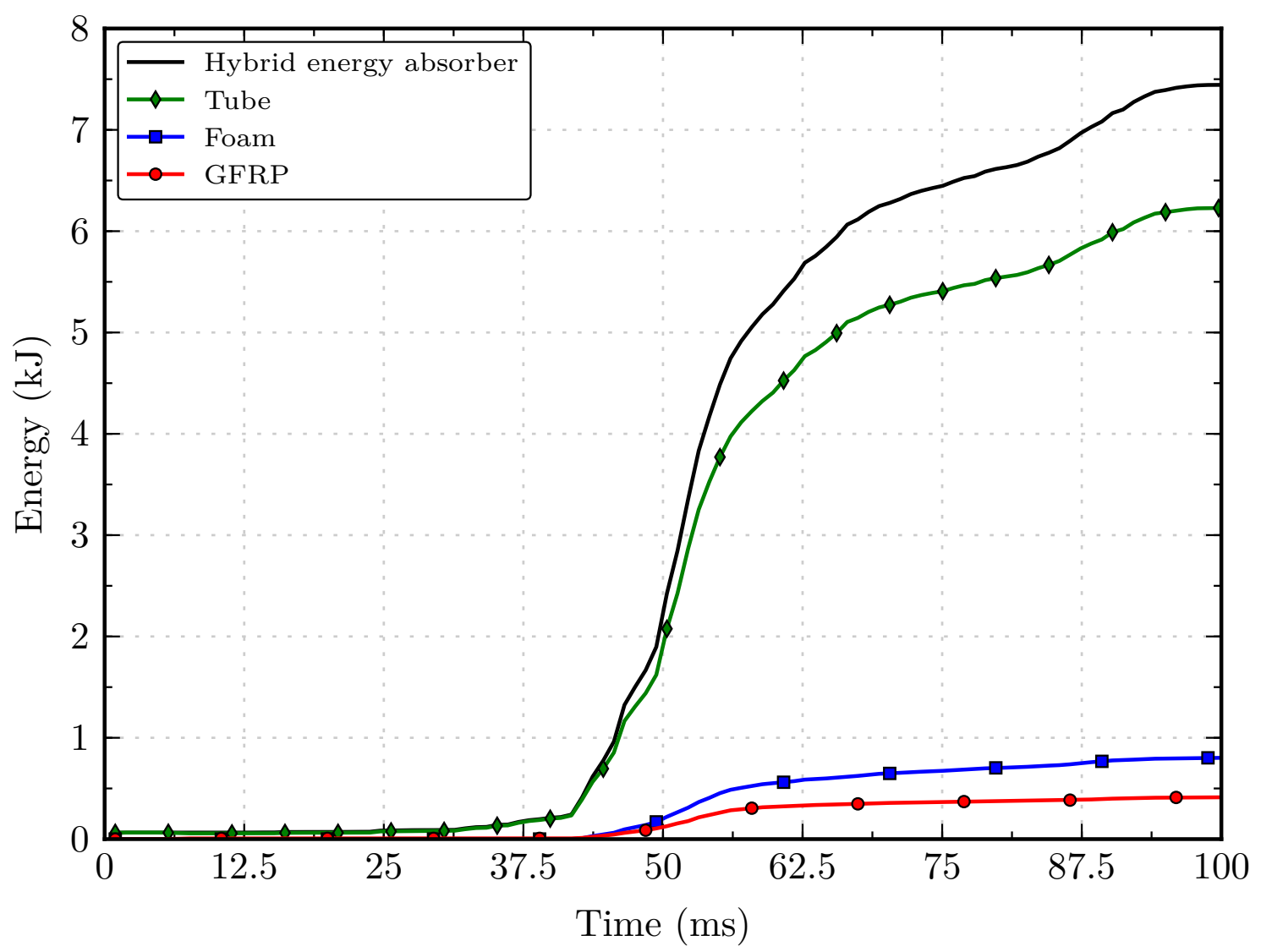

Figure 18: Plastic dissipation for the hybrid energy absorbers from model in table 9 segregated according to structural components.

energy values and trends are further looked into. The artificial-to-internal energy ratio, always below 9\%, still complies with the recommended limits for dynamic impact simulations [36, 50]. Moreover, a comparison between the original fuselage with the optimum from table 9 in terms of energy absorption by plastic deformation reveals a significant disparity on the frames' performance (see figure 19 and table 10). While these structures originally absorb $76 \mathrm{~kJ}$, this value increases over $55 \%$ to reach the $120 \mathrm{~kJ}$ mark in the enhanced fuselage, translated into a global difference of $50 \mathrm{~kJ}$. By relating the results from this energy analysis to the post-test deformations from figure 12, it can be observed how the overall structural behaviour of the aircraft is modified; with the collapse evolution after adding the struts showing a higher usage of the plastic capabilities of the frame, in addition of the energy dissipated by the devices. 


\begin{tabular}{lrrr}
\hline Model & Internal energy & Plastic dissipation & Artificial strain energy \\
\hline Original & $113.2 \mathrm{~kJ}$ & $90.5 \mathrm{~kJ}$ & $9.6 \mathrm{~kJ}$ \\
Baseline & $157.8 \mathrm{~kJ}$ & $130.1 \mathrm{~kJ}$ & $11.2 \mathrm{~kJ}$ \\
Optimum & $169.5 \mathrm{~kJ}$ & $141.2 \mathrm{~kJ}$ & $12.1 \mathrm{~kJ}$ \\
\hline
\end{tabular}

Table 10: Global internal energy, plastic dissipation and artificial strain energy values for the original fuselage, baseline design and the optimum presented in table 9.

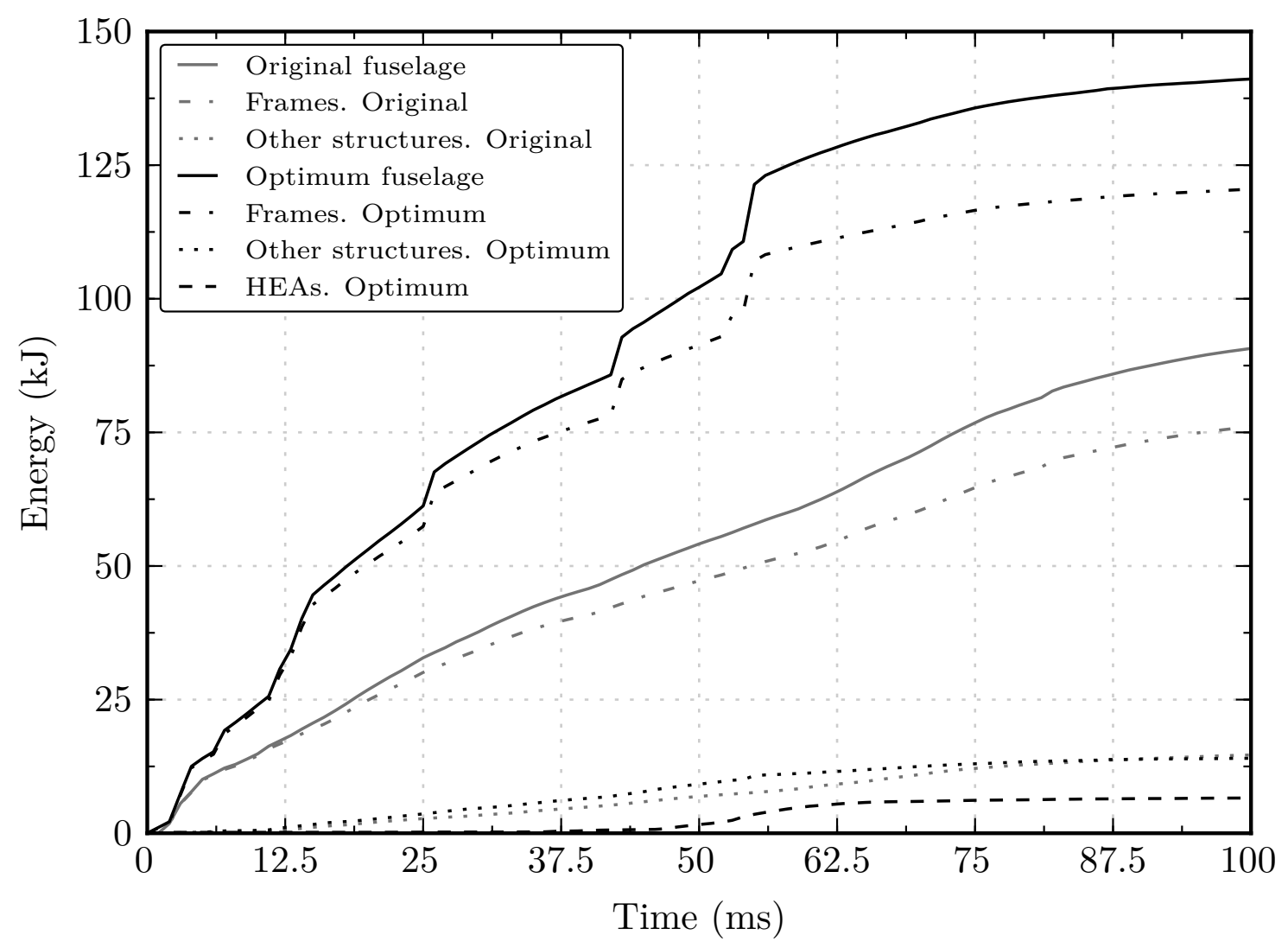

Figure 19: Energy dissipation by plastic deformation for original model and optimum from table 9. 


\section{Conclusions}

In the research described in this paper, four vertical hybrid energy absorbers are added to work as crushable vertical struts in an aircraft fuselage. The following conclusions can be withdrawn:

- A drop test simulation of a Boeing 737-200 fuselage enhanced with a baseline hybrid absorber was performed. The absorber, composed by a square aluminium tube filled with GFRP plates and foam extrusions, delivers lower peak acceleration loads at the two data extraction locations when implemented in the aircraft.

- Four variables from the baseline absorber geometric design are parametrised for executing a 600-model Latin Hypercube Sampling and the following construction of a Moving Least Squares surrogate model. This model delivers a satisfactory approximation, with low RMSE and $R^{2}$ values above 0.9 for all objective functions considered: peak acceleration at two locations $\left(A_{1}{ }^{\max }\right.$ and $\left.A_{1 \mathrm{~b}}{ }^{\max }\right)$, injury criteria $\left(A_{1}{ }^{\text {avg }}\right)$ and mass of the specimen.

- Single-objective optimisation is performed with and without the usage of constraints. Unconstrained optimisation reduced accelerations at the optimised location by over $50 \%$, but best results were delivered when applying a constraint for the acceleration at the remaining point. By enforcing constraints, accelerations are reduced by over $50 \%$ at both locations when compared to the original fuselage, while maintaining the absorber's mass under $0.5 \mathrm{~kg}$.

- Multi-objective optimisation is also performed, with two and four objective functions. A Pareto front was obtained for $A_{1}{ }^{\max }$ and $A_{1 \mathrm{~b}}{ }^{\mathrm{max}}$, where all designs improve the original and baseline fuselages. Also, trends in the variables show how low thickness values for the composite can still deliver high energy absorption values, as the interaction effect between all materials is still enabled. At the closest to the utopia point, the fuselage exhibits acceleration peaks neighbouring $25 g$ at both locations, while maintaining a mass of only $0.48 \mathrm{~kg}$.

- The usage of energy absorbers was also found to substantially affect the collapse process of the fuselage, bettering its overall response. The cargo area is less compromised, avoiding piercing of sub-floor structures with the passenger floor and maintaining a safer survivable area. In addition to the $8 \mathrm{~kJ}$ from the hybrid struts, 
the modified frames' collapse yields an overall increase in plastic dissipation of over $50 \mathrm{~kJ}$.

\section{Acknowledgements}

The research leading to these results has received funding from the Spanish Goverment (Ministerio de Economía y Competitividad) under grant agreement DPI2016-76934$\mathrm{R}$ as well as funding from the Fundación Barrié. The authors fully acknowledge the support received.

\section{Conflicts of interest}

On behalf of all authors, the corresponding author states that there is no conflict of interest.

\section{Replication of results}

All the data required to replicate the simulation and optimisation process has been detailed throughout the previous sections of the article. The numerical model used can be found in http://hdl . handle.net/2183/21615.

\section{References}

[1] Research and Innovative Technology Administration, Bureau of Transportation Statistics, Transportation Statistics Annual Report 2010, Technical Report, U.S. Department of Transportation, Washington DC, 2011.

[2] H. D. Haven, Accident survival - airplane and passenger car, Technical Report, 1952. doi:10.4271/520016.

[3] F. di Napoli, A. De Luca, F. Caputo, F. Marulo, M. Guida, B. Vitolo, Mixed FEMB methodology for the evaluation of passive safety performances of aeronautical seats, International Journal of Crashworthiness (2018) 1-12. doi:10.1080/ 13588265.2018 .1441616

[4] F. Caputo, A. De Luca, F. Marulo, M. Guida, B. Vitolo, Numerical-experimental assessment of a hybrid FE-MB model of an aircraft seat sled test, International Journal of Aerospace Engineering (2018). doi:10 . 1155/2018/8943826. 
[5] S. Heimbs, Energy absorption in aircraft structures, in: International Workshop on Hydraulic Equipment and Support Systems for Mining, Huludao, China, 2012, pp. $17-18$.

[6] P. Xue, L. Ding, F. Qiao, X. Yu, Crashworthiness study of a civil aircraft fuselage section, Latin American Journal of Solids and Structures 11 (2014) 1615-1627. doi:10.1590/s1679-78252014000900007.

[7] M. Guida, F. Marulo, S. Abrate, Advances in crash dynamics for aircraft safety, Progress in Aerospace Sciences (2018). doi:10.1016/j . paerosci.2018.03.008.

[8] L. Zhangping, X. Jinwu, Crashworthiness performance evaluation to helicopter landing gear by finite element simulation, Acta Aeronautica et Astronautica Sinica 24 (2003) 216-219.

[9] J. F. M. Wiggenraad, A. Michielsen, D. Santoro, F. Le Page, C. Kindervater, F. Beltran, M. Alkhalil, Finite element methodologies development to simulate the behaviour of composite fuselage structure and correlation with drop test, Air and Space Eur 33 (2001) 228-233. doi:10.1016/s1290-0958(01)90102-9.

[10] M. B. Woodson, E. R. Johnson, R. T. Haftka, Optimal design of composite fuselage frames for crashworthiness, International Journal of Crashworthiness 1 (1996) 369380. doi:10.1533/cras.1996.0027.

[11] Y. Ren, J. Xiang, A comparative study of the crashworthiness of civil aircraft with different strut configurations, International Journal of Crashworthiness 15 (2010) 321-330. doi:10 . 1080/13588260903343823.

[12] Y. Ren, J. Xiang, J. Zheng, Z. Luo, Crashworthiness analysis of aircraft fuselage with sine-wave beam structure, Chinese Journal of Aeronautics 29 (2016) 403-410. doi:10.1016/j.cja.2016.02.002.

[13] P. Schatrow, M. Waimer, Crash concept for composite transport aircraft using mainly tensile and compressive absorption mechanisms, CEAS Aeronautical Journal 7 (2016) 471-482. doi:10.1007/s13272-016-0203-6.

[14] Y. Ren, H. Zhang, J. Xiang, A novel aircraft energy absorption strut system with corrugated composite plate to improve crashworthiness, International Journal of Crashworthiness 23 (2018) 1-10. doi:10.1080/13588265.2017.1301082. 
[15] I. Kumakura, M. Minegishi, K. Iwasaki, T. Hosokawa, Impact simulation of simplified structural models of aircraft fuselage, 2000 World Aviation Conference. SAE transactions 109 (2000) 1238-1243. doi:10.2514/6.2000-5586.

[16] H. Shoji, M. Minegishi, T. Aoki, Channel section short column with fixed ends under axial impact load, in: 47th AIAA / ASME / ASCE / AHS / ASC Structures, Structural Dynamics, and Materials Conference, 2006, p. 1760. doi:10.2514/6. $2006-1760$.

[17] R. Yiru, X. Jinwu, L. Zhangping, Z. Jianqiang, Effect of cabin-floor oblique strut on crashworthiness of typical civil aircraft fuselage section, Acta Aeronautica Et Astronautica Sinica 2 (2010) 012.

[18] H. Shoji, M. Minegishi, T. Aoki, Impact characteristics estimation of channel section short column under axial impact load, Structural Dynamics and Materials Conference 4 (2007) 3967-3976. doi:10 . 2514/6 . 2007-2023.

[19] Y. Ren, J. Xiang, The crashworthiness of civil aircraft using different quadrangular tubes as cabin-floor struts, International Journal of Crashworthiness 16 (2011) 253262. doi:10.1080/13588265.2011.554204.

[20] M. Costas, J. Díaz, L. Romera, S. Hernández, A. Tielas, Static and dynamic axial crushing analysis of car frontal impact hybrid absorbers, International Journal of Impact Engineering 62 (2013) 166-181. doi:10 . 1016/j . i jimpeng . 2013 . 06 . 011.

[21] C. P. Gameiro, J. Cirne, V. Miranda, J. Pinho-da Cruz, F. Teixeira-Dias, Dynamic behaviour of cork and cork-filled aluminium tubes: Numerical simulation and innovative applications, Holzforschung 61 (2007) 400-405. doi:10.1515/hf . 2007. 051.

[22] M. Paulino, F. Teixeira-Dias, C. Gameiro, J. Cirne, Hyperelastic and dynamical behaviour of cork and its performance in energy absorption devices and crashworthiness applications, International Journal of Materials Engineering Innovation 1 (2009) 197-234. doi:10.1504/ijmatei. 2009.029364.

[23] T. Reddy, S. Al-Hassani, Axial crushing of wood-filled square metal tubes, International Journal of Mechanical Sciences 35 (1993) 231-246. doi:10.1016/ 0020-7403(93) 90078-9. 
[24] H. Saito, I. Kimpara, Evaluation of impact damage mechanism of multi-axial stitched CFRP laminate, Composites Part A: Applied Science and Manufacturing 37 (2006) 2226-2235. doi:10.1016/j . compositesa.2005.12.031.

[25] H. Hamada, S. Ramakrishna, A FEM method for prediction of energy absorption capability of crashworthy polymer composite materials, Journal of Reinforced Plastics and Composites 16 (1997) 226-242. doi:10.1177/073168449701600303.

[26] G. Sun, G. Li, M. Stone, Q. Li, A two-stage multi-fidelity optimization procedure for honeycomb-type cellular materials, Computational Materials Science 49 (2010) 500-511. doi:10.1016/j.commatsci.2010.05.041.

[27] A. Hanssen, M. Langseth, O. Hopperstad, Static and dynamic crushing of square aluminum extrusions with aluminum foam filler, International Journal of Impact Engineering 24 (2000) 347-383. doi:10 .1016/s0734-743x (99) 00169-4.

[28] J. Bi, H. Fang, Q. Wang, X. Ren, Modeling and optimization of foam-filled thinwalled columns for crashworthiness designs, Finite Elements in Analysis and Design 46 (2010) 698-709. doi:10.1016/j .finel . 2010.03 .008.

[29] M. Langseth, O. Hopperstad, A. Hanssen, Crash behaviour of thin-walled aluminium members, Thin-Walled Structures 32 (1998) 127-150. doi:10.1016/ s0263-8231 (98)00030-5.

[30] D. I. Gransden, R. Alderliesten, Development of a finite element model for comparing metal and composite fuselage section drop testing, International Journal of Crashworthiness 22 (2017) 401-414. doi:10 . 1080/13588265. 2016.1273987.

[31] P.-W. Chen, Y.-Y. Lin, Evaluation on crashworthiness and energy absorption of composite light airplane, Advances in Mechanical Engineering 10 (2018) 1687814018794080. doi:10.1177/1687814018794080.

[32] D. Perfetto, A. De Luca, G. Lamanna, A. Chiariello, F. Di Caprio, L. Di Palma, F. Caputo, Drop test simulation and validation of a full composite fuselage section of a regional aircraft, Procedia Structural Integrity 12 (2018) 380-391. doi:10. $1016 / j$. prostr.2018.11.079.

[33] S. Santosa, T. Wierzbicki, Crash behavior of box columns filled with aluminum 
honeycomb or foam, Computers \& Structures 68 (1998) 343-367. doi:10.1016/ s0045-7949 (98) 00067-4.

[34] A. K. Toksoy, M. Güden, The strengthening effect of polystyrene foam filling in aluminum thin-walled cylindrical tubes, Thin-walled structures 43 (2005) 333-350. doi:10.1016/j.tws. 2004.07.007.

[35] J. Paz, J. Díaz, L. Romera, M. Costas, Crushing analysis and multi-objective crashworthiness optimization of GFRP honeycomb-filled energy absorption devices, Finite Elements in Analysis and Design 91 (2014) 30-39. doi:10.1016/j.finel. 2014.07 .006$.

[36] J. Paz, L. Romera, J. Díaz, F. Teixeira-Dias, Crashworthiness study on hybrid energy absorbers as vertical struts in civil aircraft fuselage designs, International Journal of Crashworthiness. Accepted for publication Apr-01 (2019). doi:10.1080/13588265.2019.1605723.

[37] Y. Y. Tay, P. S. Bhonge, H. M. Lankarani, Crash simulations of aircraft fuselage section in water impact and comparison with solid surface impact, International Journal of Crashworthiness 20 (2015) 464-482. doi:10 . 1080/13588265 .2015.1033972.

[38] J. Paz, J. Díaz, L. Romera, M. Costas, Size and shape optimization of aluminum tubes with GFRP honeycomb reinforcements for crashworthy aircraft structures, Composite Structures 133 (2015) 499-507. doi:10.1016/j.compstruct. 2015. 07.077.

[39] J. Paz, L. Romera, J. Díaz, Crashworthiness optimization of aircraft hybrid energy absorbers enclosing honeycomb and foam structures, AIAA Journal 55 (2017) 652661. doi:10.2514/1. J055245.

[40] E. L. Fasanella, K. E. Jackson, Crash simulation of vertical drop tests of two Boeing 737 fuselage sections, in: U.S. Army Research Laboratory, Vehicle Technology Center, Langley Research Center, 2002.

[41] H. Postlethwaite, B. Mills, Use of collapsible structural elements as impact isolators, with special references to automotive applications, Journal of Strain Analysis 5 (1970) 58-73. 
[42] M. Costas, D. Morin, M. Langseth, L. Romera, J. Díaz, Axial crushing of aluminum extrusions filled with PET foam and GFRP. An experimental investigation, ThinWalled Structures 99 (2016) 45-57. doi:10.1016/j . tws .2015.11.003.

[43] M. Costas, D. Morin, M. Langseth, J. Díaz, L. Romera, Static crushing of aluminium tubes filled with PET foam and a GFRP skeleton. numerical modelling and multiobjective optimization, International Journal of Mechanical Sciences 131 (2017) 205-217. doi:10.1016/j.ijmecsci.2017.07.004.

[44] G. R. Cook, W. H. Johnson, A constitutive model and data for metals subjected to large strains, high strain rates and high temperatures, Proceedings of Seventh International Symposium on Ballistics (1983).

[45] G. Kay, Failure modeling of titanium 6AI-4V and aluminum 2024-T3 with the Johnson-Cook material model, Office of Aviation Research, Federal Aviation Administration, 2003. doi:10.2172/15006359.

[46] N. Brar, V. Joshi, B. Harris, Constitutive model constants for Al7075-T651 and Al7075-T6, in: Shock Compression of Condensed Matter 2009: Proceedings of the American Physical Society Topical Group on Shock Compression of Condensed Matter, volume 1195, AIP Publishing, 2009, pp. 945-948. doi:10.1063/1. 3295300.

[47] E. L. Fasanella, K. E. Jackson, Best practices for crash modeling and simulation, NASA/TM-2002-211944, National Aeronautics and Space Administration, Army Research Lab, Vehicle Technology Directorate, Hampton, VA (2002).

[48] BASF, Ultramid (r) A3WG10 BK00564 Polyamide 66. Product information sheet, 2012.

[49] V. Deshpande, N. Fleck, Isotropic constitutive models for metallic foams, Journal of the Mechanics and Physics of Solids 48 (2000) 1253-1283. doi:10.1016/ s0022-5096 (99)00082-4.

[50] ABAQUS 6.16 Documentation, Dassault Systèmes, 2016.

[51] Boeing Commercial Airplanes, 737 Airplane Characteristics for Airport Planning. D6-58325-6, 2013. 
[52] A. M. Eiband, Human tolerance to rapidly applied accelerations: a summary of the literature, National Aeronautics and Space Administration (NASA) (1959).

[53] B. Adams, L. Bauman, W. Bohnhoff, K. Dalbey, M. Ebeida, J. Eddy, M. Eldred, P. Hough, K. Hu, J. Jakeman, L. Swiler, D. Vigil, DAKOTA, A Multilevel Parallel Object-Oriented Framework for Design Optimization, Parameter Estimation, Uncertainty Quantification, and Sensitivity Analysis: Version 6.1.0 User's Manual, Sandia National Laboratories, 2014.

[54] J. E. Eddy, K. Lewis, Effective generation of pareto sets using genetic programming, Proceedings of ASME Design Engineering Technical Conference (2001).

[55] D. Siromani, Crashworthy design and analysis of aircraft structures, Drexel University, 2013. 